\title{
Modeling distinct vertical biogeochemical structure of the Black Sea: Dynamical coupling of the oxic, suboxic, and anoxic layers
}

T Oguz

HW Ducklow

Virginia Institute of Marine Science

P Malanotte-Rizzoli

Follow this and additional works at: https://scholarworks.wm.edu/vimsarticles

Part of the Biogeochemistry Commons, and the Environmental Chemistry Commons

\section{Recommended Citation}

Oguz, T; Ducklow, HW; and Malanotte-Rizzoli, P, "Modeling distinct vertical biogeochemical structure of the Black Sea: Dynamical coupling of the oxic, suboxic, and anoxic layers" (2000). VIMS Articles. 1412. https://scholarworks.wm.edu/vimsarticles/1412 


\title{
Modeling distinct vertical biogeochemical structure of the Black Sea: Dynamical coupling of the oxic, suboxic, and anoxic layers
}

\author{
Temel Oguz \\ Institute of Marine Sciences, Middle East Technical University, Erdemli, Icel, Turkey \\ Hugh W. Ducklow \\ College of William and Mary, Virginia Institute of Marine Sciences, Gloucester Point \\ Paola Malanotte-Rizzoli \\ Department of Earth, Atmospheric and Planetary Sciences, Massachusettes Institute of \\ Technology, Cambridge
}

\begin{abstract}
A one-dimensional, vertically resolved, physical-biogeochemical model is used to provide a unified representation of the dynamically coupled oxic-suboxicanoxic system for the interior Black Sea. The model relates the annual cycle of plankton production in the form of a series of successive phytoplankton, mesozooplankton, and higher consumer blooms to organic matter generation and to the remineralization-ammonification-nitrification-denitrification chain of the nitrogen cycle as well as to anaerobic sulfide oxidation in the suboxic-anoxic interface zone. The simulations indicate that oxygen consumption during remineralization and nitrification, together with a lack of ventilation of subsurface waters due to the presence of strong stratification, are the two main factors limiting aerobic biogeochemical activity to the upper $\sim 75 \mathrm{~m}$ of the water column, which approximately corresponds to the level of nitrate maximum. The position of the upper boundary and thus the thickness of the suboxic layer are controlled by upper layer biological processes. The quasi-permanent character of this layer and the stability of the suboxic-anoxic interface within the last several decades are maintained by a constant rate of nitrate supply from the nitrate maximum zone. Nitrate is consumed to. oxidize sinking particulate organic matter as well as hydrogen sulfide and ammonium transported upward from deeper levels.
\end{abstract}

\section{Introduction}

\subsection{General Characteristics of the Vertical Biogeochemical Structure}

Two distinct features of the vertical biogeochemical structure of the Black Sea are the oxygen deficiency and nitrogen depletion of the subsurface waters. Because of weak vertical mixing due to the presence of a strong density stratification and poor ventilation of deep waters by lateral influxes, the sub pycnocline waters are permanently anoxic. The predominant vertical gradients of biogeochemical properties are confined within the strongly stratified upper $100 \mathrm{~m}$ layer, in which den-

Copyright 2000 by the American Geophysical Union.

Paper number 1999GB001253.

0886-6236/00/1999GB001253\$12.00 sity changes by $\sim 5 \mathrm{~kg} \mathrm{~m}^{-3}$ from $\sigma_{t} \sim 11.0$ at the surface to $\sigma_{t} \sim 16.0 \mathrm{~kg} \mathrm{~m}^{-3}$ at $100 \mathrm{~m}$ depth.

A conceptual model of the present state of the Black Sea biogeochemical structure is shown in Figure 1. Four distinct layers are identified in this system. The euphotic zone extends from the free surface to the depth of the $1 \%$ light level and has a maximum thickness of $\sim 50 \mathrm{~m}$. This is the layer of active aerobic planktonic processes and is also characterized by high oxygen concentrations of the order of $300 \mu \mathrm{M}$. The uppermost 20 $30 \mathrm{~m}$ of the aphotic zone is called the oxycline/upper nitracline zone in which oxygen concentration reduces to $\sim 10 \mu \mathrm{M}$, whereas nitrate concentration increases to around 6-8 $\mu \mathrm{M}$. In the subsequent oxygen-deficient layer of $\sim 30 \mathrm{~m}$, known as the Suboxic Layer (SOL), nitrate concentrations undergo a sharp decrease to trace values $(\sim 0.1 \mu \mathrm{M})$ [Murray et al., 1989; Basturk et al., 1994, 1997; Buesseler et al., 1994; Eremeev, 1996]. The 


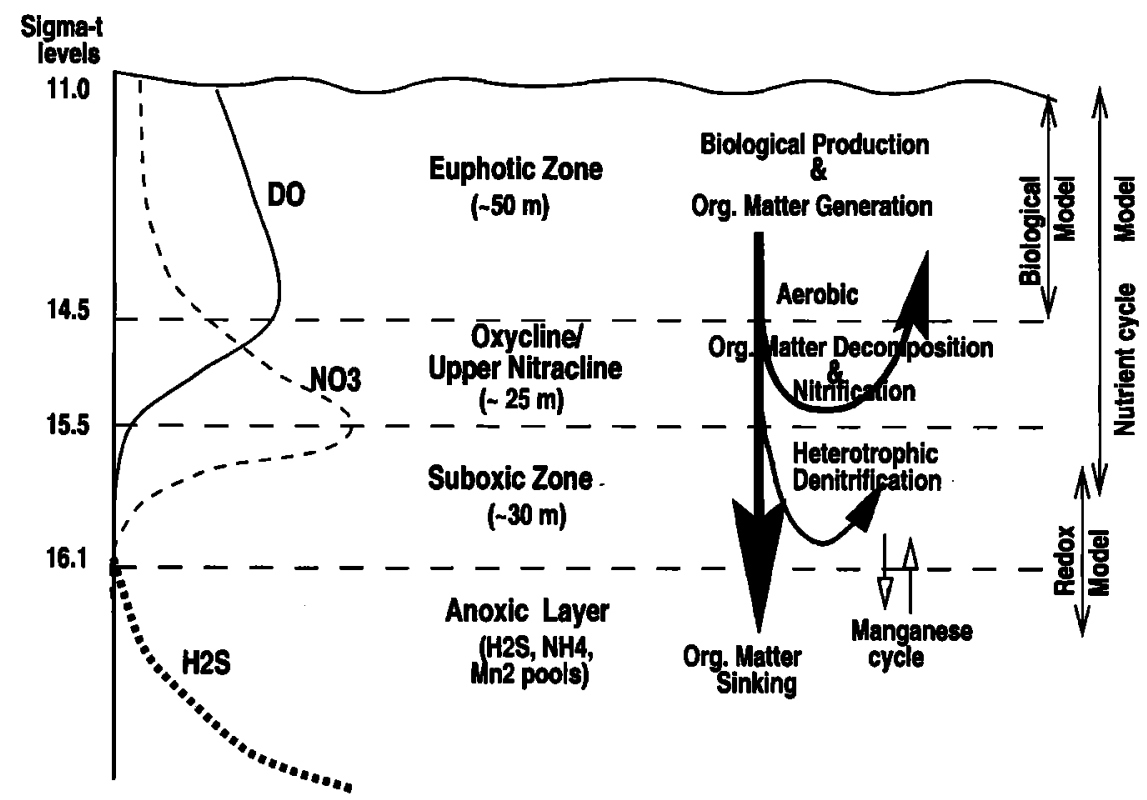

Figure 1. Schematic diagram of the biogeochemical structure of the upper layer water column in the Black Sea.

SOL is followed by a deep anoxic layer characterized by large hydrogen sulfide and ammonium pools. The suboxic-anoxic interface zone involves a complicated series of bacterially mediated redox reactions [Murray et al., 1995, 1999; Rozanov, 1996]. These reactions control the downward transport of nitrate and the upward transports of ammonium and sulfide near the interface zone. The suboxic layer most commonly exists as very thin layers with steep chemical gradients in sediments of rivers and other eutrophic systems [Thomsen and Kristensen, 1997; Neumann et al., 1998] but also exists in the major hypoxic ocean basins [Warren, 1994]. However, it is most easily studied in the Black Sea owing to the great physical stability of the water column, which enabled accurate resolution of the oxygen and sulfide gradient structure. Physical stability seems to maintain a well-defined redox structure which constitutes one of the unique characteristics of the Black Sea biogeochemical system.

The biogeochemical structure shown in Figure 1 reflects the state of the Black Sea ecosystem after the 1970s, following intense eutrophication and ecological deterioration as a result of large inputs of nutrients and contaminants introduced from the Danube, Dniestr, and Dniepr Rivers to the northwestern shelf. The available data indicate subsequent, dramatic changes at all trophic levels [Mee, 1992; Zaitsev and Mamaev, 1997; Ozsoy and Mikaelyan, 1997; Ivanov and Oguz, 1998]. The average phytoplankton biomass increased by an order of magnitude, with profound changes in taxonomic composition [Zaitsev, 1993; Vinogradov et al.,
1999]. Many of the dominant mesozooplankton species supporting fish populations were replaced by smaller and less valuable species, as well as by the opportunistic species Noctiluca scintillans, Aurelia aurita, Pleurobrachia, and Mnemiopsis leidyi [Shushkina et al., 1998; Kovalev et al., 1998; Shiganova et al., 1998; Mutlu, 1999; Kideys et al., 2000].

These transformations in the phytoplankton and mesozooplankton levels of the ecosystem were also accompanied by an apparent increase in organic matter content of the upper water column [Konovalov et al., 1999], enhanced bacterial production and organic matter decomposition [Vinogradov et al., 1999], and subsequently higher rates of oxygen consumption. Consequently, the dissolved oxygen gradient zone shifted gradually upward in the 1970s and 1980s [Basturk et al., 1998], even though onset of the oxycline (around $\sigma_{t} \sim 14.5 \mathrm{~kg} \mathrm{~m}^{-3}$ ) and the position of the sulfide interface (around $\sigma_{l} \sim 16.1 \mathrm{~kg} \mathrm{~m}^{-3}$ ) remained unchanged (Figure 2a). A somewhat steeper oxycline implies an upward expansion and broadening of the oxygen deficient suboxic layer [Konovalov et al., 1999].

More active organic matter decomposition also led to higher rates of nitrogen production within the oxygenated part of the water column and of nitrogen consumption due to denitrification further below. Comparision of nitrate profiles measured 20 years apart [Tugrul et al., 1992; Kempe, 1995] suggested an upward elevation of the position of the nitrate peak from the density level of $\sigma_{t} \sim 15.8$ to $\sim 15.5 \mathrm{~kg} \mathrm{~m}^{-3}$ ( $\sim 10 \mathrm{~m}$ within the cyclonically-dominated interior Black Sea). The 

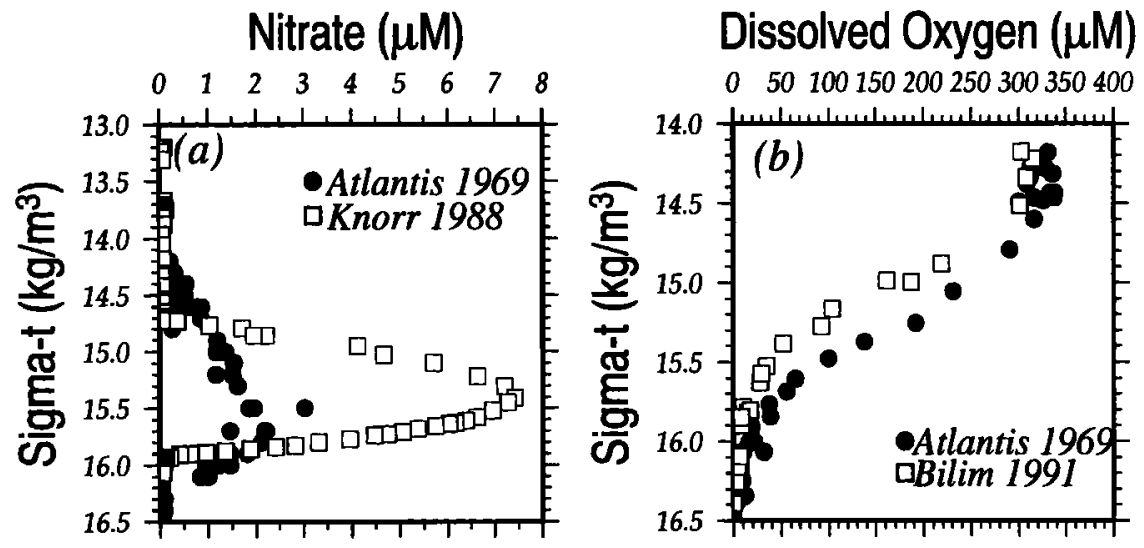

Figure 2. (a) The dissolved oxygen $(\mu \mathrm{M})$, and (b) the nitrate $(\mu \mathrm{M})$ profiles versus sigma-t (kg $\mathrm{m}^{-3}$ ) measured during the R/V Atlantis 1969 (solid circles) and R/V Bilim 1991 (open squares) surveys.

magnitude of the peak also increased from $\sim 3.0 \mu \mathrm{M}$ to $\sim 8.0 \mu \mathrm{M}$ during this period as a result of continuous nutrient supply from rivers (Figure $2 b$ ).

\subsection{Existing Modeling Studies}

The modeling efforts given by Lebedeva and Shushkina [1994], Oguz et al. [1996, 1998, 1999], Gregoire et al. [1998], and Lancelot et al. [2000] dealt only with simulations of the upper layer plankton system. Oguz et al. [1996] presented a one-dimensional, vertically resolved, coupled physical-biogeochemical model with single groups of phytoplankton and zooplankton, detritus, ammonium, and nitrate. This model was later extended to a slightly more complex form [Oguz et al., 1998, 1999], distinguishing two major classes of phytoplankton (diatoms and flagellates) and two dominant zooplankton size groups (microzooplankton and mesozooplankton). The model was further modified by introducing a simple microbial loop, two distinct groups of gelatinous carnivores (Aurelia aurita and Mnemiopsis leidyi), and the opportunistic species Noctiluca scintillans ( $\mathrm{T}$. Oguz et al., Modeling the response of topdown control exerted by gelatinous carnivores on the Black Sea pelagic food web, submitted to Journal of Geophysical Research, 2000) (hereinafter referred to as Oguz et al., submitted manuscript, 2000) The latter model was then used to investigate how top-down control by gelatinous carnivores operated during the last two decades in the Black Sea ecosystem. A one dimensional model with comparable ecosystem complexity, but considering only bulk properties over the euphotic layer was used to study the northwestern shelf ecosystem [Lancelot et al., 2000] and the interior basin ecosystem [Lebedeva and Shushkina, 1994]. Effects of shelf-deep basin interactions on the northwestern shelf ecosystem were explored by Gregoire et al. [1998] using a three-dimensional physical-biological model.

Few modeling studies have addressed nitrogen and sulfur cycles in the oxic-anoxic interface region of the Black Sea [Yakushev and Neretin, 1997; Oguz et al., 2000]. These models were restricted to the interface region and were therefore decoupled from euphotic zone biological processes. In the Yakushev and Neretin [1997] model, oxygen was the only oxidant to drive the sulfur cycle. In contrast to the observed oxygen and sulfide depleted suboxic zone [Murray et al., 1989], their simulations showed overlapping dissolved oxygen and sulfide concentrations in the region between oxygenated waters and the anoxic pool. However, no dynamical reasoning was offered for this coexistence layer. It appeared to be a consequence of the choice of higher vertical eddy diffusivity, which caused an appreciably higher downward oxygen flux into the interface zone. Belyaev et al. [1997] and Lyubartseva and Lyubartsev [1998] applied a similar model of oxygen-sulfide interactions to the northwestern shelf region.

Oguz et al. [2000] proposed a model with a somewhat different set of redox reactions catalyzed by the manganese cycle. The model was based on the hypothesis that the anaerobic sulfide oxidation and nitrogen transformations were the primary mechanisms controlling the interface structure between the suboxic and anoxic layers. Following Murray et al. [1995, 1999], it was proposed that the upward fluxes of sulfide and ammonium are oxidized by $\mathrm{Mn}$ (III, IV) and Fe(III) species, whereas the downward flux of nitrate may be reduced by dissolved manganese and ammonium. Mn(II) oxidation and $\mathrm{Mn}$ (IV) reduction are both microbially catalyzed [Tebo, 1991, 1998; Francis and Tebo, 1999], but dissolved abiotic, chemical reduction is also thought to 
play a role in $\mathrm{Mn}(\mathrm{IV})$ reduction. In Oguz et al. [2000], only manganese cycling was included, and the additional contribution of iron cycling was neglected for simplicity. Even with such a highly simplified representation of the redox processes, the model provided a realistic suboxic-anoxic interface zone structure and was able to give quantitative evidence for the presence of an oxygen depleted and nonsulfidic suboxic zone. This model pointed out the crucial role of the downward supply of nitrate from the overlying nitracline zone and the upward transport of dissolved manganese from the anoxic pool below for maintenance of the suboxic layer. Oxidation of dissolved manganese by nitrate was found to be responsible for the production and cycling of particulate manganese, which in turn oxidized hydrogen sulfide and ammonium transported upward from deeper levels. This mechanism was shown to lead to a quasi-steady state suboxic-anoxic interface structure similar to observations.

\subsection{Aims and Scope of the Present Study}

As pointed out in section 1.2, a comprehensive model providing a unified representation of the oxic-suboxicanoxic system in the Black Sea is not yet available. The existing models were devoted either to representation of euphotic zone processes (e.g., plankton productivity) or separately to suboxic-anoxic interactions. Without a coupled model of these two distinct biogeochemical layers, we cannot realistically investigate the underlying dynamics of the full water column. In light of evidence that biological fluxes have a considerable impact on suboxic zone dynamics (see Figures $2 a$ and $2 b$ ), a model of the dynamically coupled oxic-suboxic-anoxic system is a prerequisite for understanding the development of Black Sea biogeochemistry over the last three decades. The model presented here serves this purpose and is designed specifically to describe the perturbed ecosystem conditions of the late 1970s and 1980s (dominated by gelatinous and opportunistic species) and subsequently modified oxycline/nitracline and suboxic zone structures. Observations carried out in the 1990s indicated the stability of this structure with slight modifications in oxygen and nitrate concentrations and in the slopes of the nitracline and oxycline [Konovalov et al., 1997, 1999; Basturk et al., 1997].

The model presented here is an extension of our previous simulations of the carnivore-dominated Black Sea ecosystem (Oguz et al., submitted manuscript, 2000) and redox cycling across the suboxic-anoxic interface zone [Oguz et al., 2000]. It is applied for the interior Black Sea, which possesses a simpler structure, compared to that in the shelf areas. The nitrogen and redox cycle models are calibrated and verified by the Knorr 1990 data [Friedrich et al., 1990], which constitute the best and most complete available data set acquired dur- ing the relevant period [Murray et al., 1989]. The biological model simulations are verified by biweekly time series measurements obtained off Gelendzhik (northeastern Black Sea) during 1978 [Shushkina et al., 1983]. The Gelendzhik data define the main features of the annual plankton cycle suggested by other data sets collected during the 1980s [Shushkina et al., 1998; Nezlin et al., 1999] prior to the population explosion of another gelatinous carnivore, Mnemiopsis leidyi, in the 1989-1991 period. Thus, although they were made 10 years apart, the 1978 biological measurements and 1988 chemical measurements used here belong to the same ecosystem period. They were chosen simply because of their quality and coverage.

The major goal of the paper is to explore the underlying mechanisms which maintain the stability of the biogeochemical structure (Figure 1) over a decadal timescale. The model is used to simulate the distinct features of the water column biogeochemical structure outlined in Figure 1. It addresses specifically questions on (1) ventilation characteristics and mechanisms governing oxygen production/consumption in the water column; (2) seasonal variability of the suboxic layer in terms of its characteristics and thickness; and (3) the relative roles of nitrification-denitrification and $\mathrm{H}_{2} \mathrm{~S}$ oxidation processes for controlling the structure of the suboxic layer from its upper and lower boundaries, respectively. A detailed description of the model formulation is given in section 2 . The results of a specific simulation are then discussed in section 3. A summary and main conclusions are presented in section 4 .

\section{Model Formulation}

Our strategy was to model the Black Sea vertical biogeochemical structure above the deep anoxic pool as simply as possible with a minimum number of unknowns and of poorly defined parameters. At the same time, we must retain sufficient complexity in the model to provide reasonably realistic simulations. Because only $\sim 10 \%$ of the primary production is exported into the deeper levels of water column and the rest is recycled efficiently from the surface to the suboxic-anoxic interface zone [Karl and Knauer, 1991; Kempe, 1991], our model excludes complicated sulfur cycling within the deep, anoxic part of the water column.

A nitrogen-based model of the pelagic plankton system is coupled through particulate and dissolved organic matter fluxes to the water column nitrogen cycle model involving transformations among ammonium, nitrite, and nitrate. These models are also coupled with a model of oxygen and redox dynamics describing oxygen variations within the water column and various oxidation-reduction reactions near the suboxic-anoxic interface zone. The oxidation-reduction reactions in the 
nitrogen cycle, as well as manganese and sulfur transformations, are modeled without adding state variables for the organisms involved (nitrifiers, $\mathrm{Mn}$ and $\mathrm{H}_{2} \mathrm{~S}$ oxidizers etc.). Ideally these populations would be modeled as we now model carbon transformations [e.g., Walsh et al., 1999], but lack of specific local data on the groups involved present a barrier to a more comprehensive approach at this time. Data on biomass levels and estimates of biomass-specific constants would provide useful constraints for such a model. For now, we model these transformations as chemical reactions recognizing that they are in fact biologically mediated.

The biogeochemical model has an on-line coupling with the physical model through vertical eddy diffusivity and temperature. The physical model, which has been documented previously by Oguz et al. [1996], is based on a one-dimensional version of the Princeton Ocean Model in which wind- and buoyancy-induced vertical mixing are parameterized by a level 2.5 turbulence closure model.

As given by Oguz et al. [1996, 1999], the local temporal variations of all biogeochemical variables are expressed by equations of the general form

$$
\frac{\partial F}{\partial t}+\frac{\partial\left(w_{b} F\right)}{\partial z}=\frac{\partial}{\partial z}\left[\left(K_{b}+\nu_{b}\right) \frac{\partial F}{\partial z}\right]+\Re(F),
$$

where $F$ denotes any state variable of the biogeochemical model, $t$ is time, $z$ is the vertical coordinate, $\partial$ denotes partial differentiation, $K_{b}$ is the vertical turbulent diffusion coefficient, $\nu_{b}$ is its background value representing mixing associated with internal waves, $w_{b}$ is the sinking velocity (only for diatoms, detritus, and particulate manganese), and $\Re(F)$ is the interaction term expressed as a balance of sources and sinks for each of the state variables. A detailed description of the biological source-sink terms is provided in section 2.1.

\subsection{Biological Model}

The biological model represents the pelagic foodweb with two groups of phytoplankton (diatoms $\mathrm{P}_{\boldsymbol{d}}$, phytoflagellates $\mathrm{P}_{f}$ ), two classes of herbivorous/ omnivorous zooplankton (microzooplankton $\mathrm{Z}_{s}$ with size less than $200 \mu \mathrm{m}$, mesozooplankton $\mathrm{Z}_{l}$ with size $0.2-2$ $\mathrm{mm}$ ), nonphotosynthetic free living bacterioplankton B, the gelatinous carnivore group $\mathrm{Z}_{m}$ of medusae Aurelia aurita, and an opportunistic species group $\mathrm{Z}_{n}$ representing the omnivorous dinoflagellate Noctiluca scintillans. The microzooplankton compartment represents heterotrophic flagellates and ciliates and establishes a link between the microbial loop and higher trophic levels in the model foodweb. The mesozooplankton compartment represents copepods, cladocerans, and appendicularians. They feed primarily on diatoms, detritus, and microzooplankton. The jellyfish Aurelia prey on mesozooplankton, whereas Noctiluca consumes mainly detritus, microzooplankton, and some phytoplankton. A schematic diagram of the prey-predator interactions among all plankton groups, as well as linkage to the model of nitrogen cycling, is shown in Figure 3a.

As discussed by (Oguz et al., submitted manuscript, 2000 ), the 1980 s ecosystem cannot be represented realistically, consistent with observations, without a plankton model of this level of detail. However, our preliminary experiments suggested that such biological complexity was not necessary for simulation of the nitrogen structure of the subsurface levels. A simpler biological model may indeed provide sufficient nitrogen flux from the euphotic zone to support a realistic biogeochemical structure within the deeper part of the upper-layer water column. In fact, simulations using a simpler model without suboxic-anoxic layer interactions [Oguz et al., 1999] were quite successful for reproducing major features of the nitrogen cycling in the water column. In another study with an even simpler system [Oguz et $a l ., 2000$ ], we neglected euphotic zone biological processes altogether and parameterized their impacts by specifying a nitrogen flux as an upper boundary condition. This simple model was shown to generate a realistic suboxic layer structure for a particular range of values of vertical eddy diffusivity and rate constants of biogeochemical reactions. However, one of our longerterm interests is to use the present model for investigating temporal evolution of the pelagic ecosystem since 1960 s and its impacts on the biogeochemical structure of deeper waters (cf. Figure 2). We therefore retain complexity in the biological model to form a baseline and to complement our future studies.

Source/sink terms for the biological model are described for each compartment by

$$
\begin{aligned}
\Re\left(P_{f}\right)= & (1-\chi) \sigma_{f} \Phi P_{f}-G_{s}\left(P_{f}\right) Z_{s} \\
& -G_{l}\left(P_{f}\right) Z_{l}-G_{n}\left(P_{f}\right) Z_{n}-\lambda_{f} P_{f}^{2} \\
\Re\left(P_{d}\right)= & (1-\chi) \sigma_{d} \Phi P_{d}-G_{s}\left(P_{d}\right) Z_{s} \\
& -G_{l}\left(P_{d}\right) Z_{l}-G_{n}\left(P_{d}\right) Z_{n}-\lambda_{d} P_{d}^{2} \\
\Re\left(Z_{s}\right)= & \gamma_{s}\left[G _ { s } \left(P_{f}+G_{s}\left(P_{d}\right)+G_{s}(D)\right.\right. \\
& \left.+G_{s}(B)\right] Z_{s}-\left[G_{l}\left(Z_{s}\right) Z_{l}+G_{m}\left(Z_{s}\right) Z_{m}\right. \\
& \left.+G_{n}\left(Z_{s}\right) Z_{n}\right]-\mu_{s} Z_{s}-\lambda_{s} Z_{s} \\
\Re\left(Z_{l}\right)= & \gamma_{l}\left[G_{l}\left(P_{f}\right)+G_{l}\left(P_{d}\right)+G_{l}(D)+G_{l}\left(Z_{s}\right)\right. \\
& \left.+G_{l}\left(Z_{n}\right)\right] Z_{l}-G_{m}\left(Z_{l}\right) Z_{m}-\mu_{l} Z_{l}-\lambda_{l} Z_{l} \\
\Re\left(Z_{n}\right)= & \gamma_{n}\left[G_{n}\left(Z_{s}\right)+G_{n}\left(P_{f}\right)+G_{n}\left(P_{d}\right)\right. \\
& \left.+G_{n}(D)\right] Z_{n}-G_{n}\left(Z_{n}\right) Z_{l}-\mu_{n} Z_{n}-\lambda_{n} Z_{n} \\
\Re\left(Z_{m}\right)= & \gamma_{m}\left[G_{m}\left(Z_{s}\right)+G_{m}\left(Z_{l}\right)\right] Z_{m} \\
& -\mu_{m} Z_{m}-\lambda_{m} Z_{m} \\
\Re(B)= & {\left[G_{b}(D O N)+G_{b}(D)\right] B-G_{s}(B) Z_{s}-\mu_{s} B . }
\end{aligned}
$$

A balance between net primary production (the first terms on the right hand sides of (2a) and (2b)), losses 

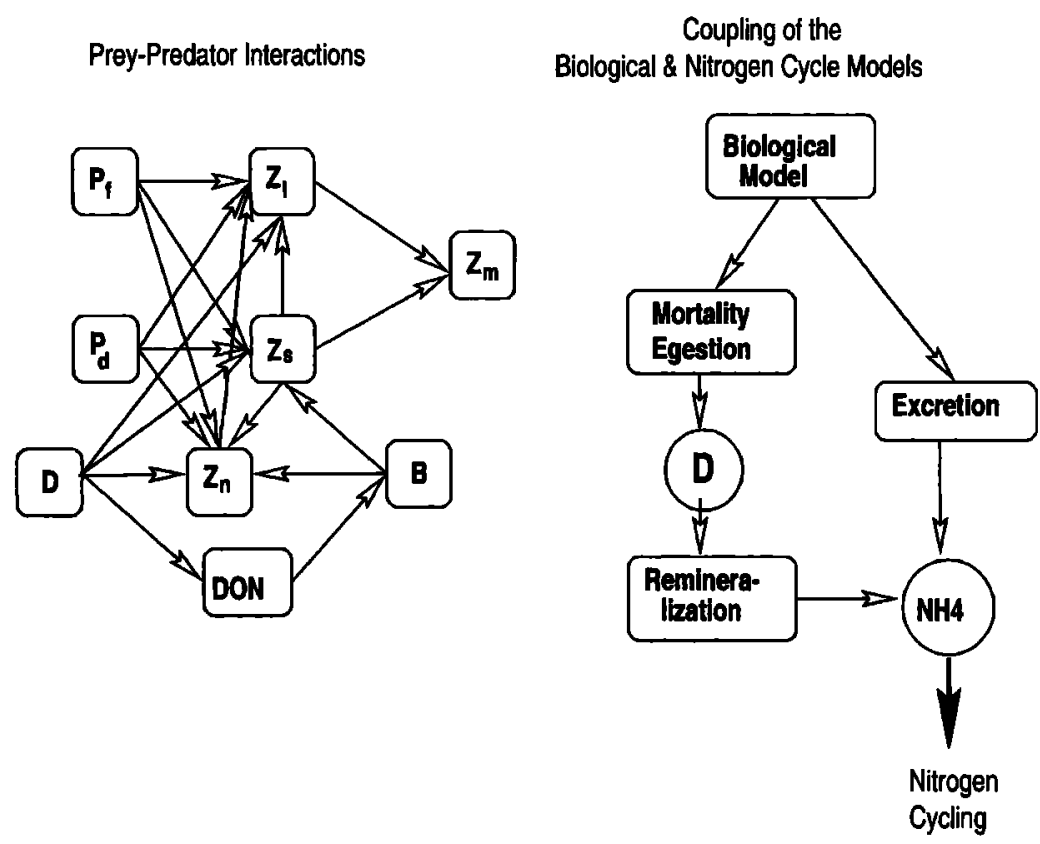

Figure 3a. (left) Prey-predator interactions between plankton groups of the Black Sea pelagic foodweb, and (right) coupling of the biological model with the model of nitrogen cycle. Notation as in text.

due to zooplankton grazing (the terms inside the square brackets) and physiological mortality (the last terms) controls temporal variations in the phytoplankton biomass. The effects of respiration and phytoplankton excretion are included in the mortality terms. A fraction of the primary production is exuded as dissolved organic nitrogen (DON). Inorganic nitrogen is the only limiting nutrient for phytoplankton growth under central Black Sea conditions. Potential silicate limitation on diatom growth is therefore not addressed.

Phytoplankton growth in (2a) and (2b) is modeled as a product of the maximum specific growth rate, an overall limitation function and phytoplankton biomass. The overall limitation function is defined by

$$
\Phi=\min \left[\alpha(I), \beta_{t}\left(N O_{3}, N H_{4}\right)\right] f(T)
$$

where min denotes the minimum of the light limitation function $\alpha(I)$, and the nutrient limitation function $\beta_{t}\left(N_{3}, N H_{4}\right)$, and the function $f(T)$ represents temperature control on the growth. They are expressed by

$$
\begin{gathered}
\alpha(I)=\tanh [a I(z, t)] \\
\beta_{t}\left(N O_{3}, N H_{4}\right)=\beta_{n}\left(N O_{3}\right)+\beta_{a}\left(N H_{4}\right) \\
f(T)=Q_{10}^{(T-20) / 10}
\end{gathered}
$$

The nutrient-limited growth (equation (3b)) is the sum of ammonium limitation function $\beta_{a}\left(\mathrm{NH}_{4}\right)$, and the nitrate limitation function $\beta_{n}\left(\mathrm{NO}_{3}\right)$ given by

$$
\begin{gathered}
\beta_{n}\left(N O_{3}\right)=\left[N O_{3} /\left(R_{n}+N O_{3}\right)\right] \exp \left(-\psi N H_{4}\right) \\
\beta_{a}\left(N H_{4}\right)=N H_{4} /\left(R_{a}+N H_{4}\right)
\end{gathered}
$$

Light limitation (equation (3b)) is parameterized according to Jassby and Platt [1976] by assuming that photosynthetically available solar radiation at the sea surface, $I_{s}$, decays exponentially with depth according to a total extinction parameter due to water itself and phytoplankton and detritus content:

$$
I(z, t)=I_{s} \exp \left[-\left(k_{w}+k_{c}\left(P_{d}+P_{f}+D\right)\right) z\right]
$$

Ingestion, predation, mortality, and excretion are the major processes controlling changes in the zooplankton biomass. Ingestion is represented by the group of terms inside the first square brackets in (2c)-(2e). The second square brackets in (2c) and the subsequent term in each of (2d) and (2e) represents predation by higher predators. The last two terms define excretion and mortality, respectively. The present model considers a simple microbial loop in which organic nitrogen constitutes the sole source for heterotrophic bacteria to meet their nitrogen requirements (the first term in (2g)). We therefore ignore the role of ammonium uptake [Walsh et al., 1999]. Detritus constitutes a secondary source of nitrogen for bacterial growth. Grazing on bacterioplankton by microzooplankton and mesozooplankton (the terms inside the square brackets), and mortality (the last term) represent the sink terms.

The growth/grazing rates in (2a)-(2g) are represented, except for Aurelia, by the Michaelis-Menten function 


$$
G_{i}\left(\psi_{j}\right)=r_{i} f_{i}(T) \frac{a_{j} \varphi_{j}}{R_{i}+\sum_{n} a_{n} \varphi_{n}}
$$

where the maximum rate $r_{i}$ is controlled by the temperature limitation function $f(T)$, individual food content $\varphi_{j}$, and food capture efficiency coefficients $a_{j}$. For $A u$ relia, the grazing rate has a linear form with a time dependent maximum rate specification

$$
G_{m}\left(\psi_{j}\right)=r_{m}(t) f_{m}(T) \frac{a_{j} \varphi_{j}}{\sum_{n} a_{n} \varphi_{n}}
$$

\subsection{Nitrogen Cycle Model}

The nitrogen cycle model incorporates transformation of sinking labile organic detritus to organic and inorganic nitrogen forms and relates euphotic zone biological production to the remineralization-ammonificationnitrification-denitrification chain in the water column. These processes are formulated by introducing the labile pelagic detritus $\mathrm{D}$, dissolved organic nitrogen $\mathrm{DON}$, nitrate $\mathrm{NO}_{3}$, nitrite $\mathrm{NO}_{2}$, and ammonium $\mathrm{NH}_{4}$ compartments. The elements of the nitrogen cycle model and the processes incorporated are shown schematically in Figure $3 \mathrm{~b}$. The corresponding source/sink terms are given by

$$
\begin{aligned}
& \Re(D)=\left(1-\gamma_{s}\right)\left[G_{s}\left(P_{f}\right)+G_{s}\left(P_{d}\right)+G_{s}(B)\right] Z_{s} \\
& \quad+\left(1-\gamma_{l}\right)\left[G_{l}\left(P_{f}\right)+G_{l}\left(P_{d}\right)+G_{l}\left(Z_{s}\right)\right. \\
& \left.\quad+G_{l}\left(Z_{n}\right)\right] Z_{l}+\left(1-\gamma_{m}\right)\left[G_{m}\left(Z_{s}\right)+G_{m}\left(Z_{l}\right)\right] Z_{m} \\
& \quad+\left(1-\gamma_{n}\right)\left[G_{n}\left(Z_{s}+G_{n}\left(P_{f}\right)+G_{n}\left(P_{d}\right)\right] Z_{n}\right. \\
& \quad+\left[\lambda_{f} P_{f}^{2}+\lambda_{d} P_{d}^{2}+\lambda_{s} Z_{s}+\lambda_{l} Z_{l}+\lambda_{m} Z_{m}\right. \\
& \left.\quad+\lambda_{n} Z_{n}\right]-\left[\gamma_{s} G_{s}(D) Z_{s}+\gamma_{l} G_{l}(D) Z_{l}\right. \\
& \left.\quad+\gamma_{n} G_{n}(D) Z_{n}+G_{b}(D) B\right]-\epsilon\left[f_{n}\left(O_{2}\right)+f_{d}\left(O_{2}\right)\right] D \\
& \Re(D O N)=\chi\left[\sigma_{f} \Phi P_{f}+\sigma_{d} \Phi P_{d}\right]+(1-\kappa) \\
& \quad\left[f_{n}\left(O_{2}\right)+f_{d}\left(O_{2}\right)\right] D-G_{b}(D O N) B \\
& \Re\left(N H_{4}\right)=\kappa \epsilon\left[f_{n}\left(O_{2}\right)+f_{d}\left(O_{2}\right)\right] D-\Phi\left(\frac{\beta_{a}}{\beta_{t}}\right) \\
& \quad\left(\sigma_{f} P_{f}+\sigma_{d} P_{d}\right)+\left[\mu_{s} Z_{s}+\mu_{l} Z_{l}+\mu_{m} Z_{m}+\mu_{n} Z_{n}\right. \\
& \left.\quad+\mu_{b} B\right]-k_{1} f_{n}\left(O_{2}\right) N H_{4}-k_{8} N H_{4} M n O_{2} \\
& \Re\left(N O_{2}\right)=k_{1} f_{n}\left(O_{2}\right) N H_{4}-k_{2} f_{n}\left(O_{2}\right) N O_{2} \\
& \quad+k_{3} f_{d}\left(O_{2}\right) N O_{3}-k_{4} f_{d}\left(O_{2}\right) N O_{2} \\
& \Re\left(N O_{3}\right)=k_{2} f_{n}\left(O_{2}\right) N O_{2}-k_{3} f_{d}\left(O_{2}\right) N O_{3} \\
& \quad-\Phi\left(\frac{\beta_{n}}{\beta_{t}}\right)\left(\sigma_{s} P_{s}+\sigma_{l} P_{l}\right)-\alpha_{7} k_{7} N O_{3} M n^{2+}
\end{aligned}
$$

Fecal pellets, constituting the unassimilated part of ingested food (the group of terms inside the first four square brackets in (4a), as well as dead phytoplankton and zooplankton (the terms inside the fifth square bracket) are the sources of labile particulate organic matter. They are recycled in the water column as a result of utilization by zooplankton and bacteria (the

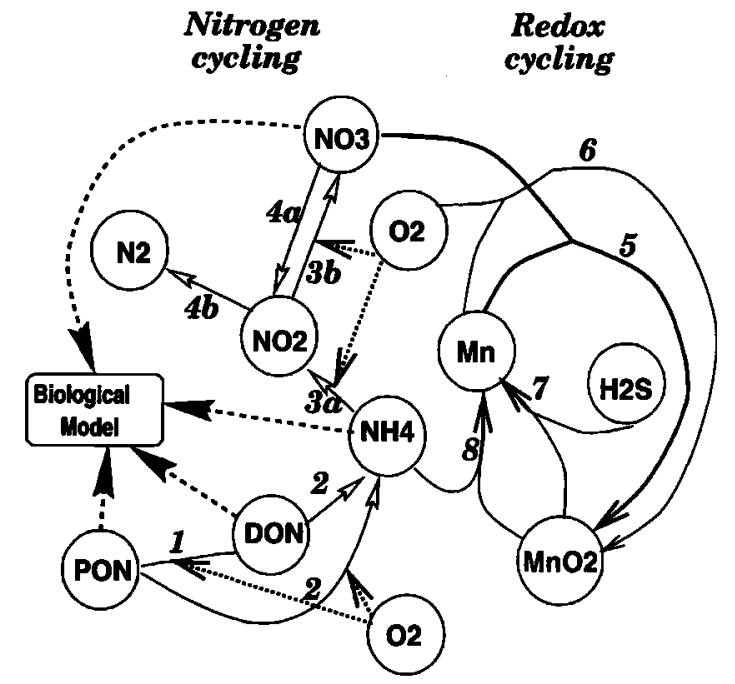

Figure 3b. Pathways of biogeochemical transformations constituting elements of the nitrogen and redox cycles in the model. The numbers refer to remineralization (1), ammonification (2), first step of nitrification (3a), second step of nitrification (3b), first step of denitrification (4a), second step of denitrification (4b), oxidation of dissolved manganese by nitrate (5), oxidation of dissolved manganese by dissolved oxygen (6), oxidation of hydrogen sulfide by particulate manganese (7), oxidation of ammonium by particulate manganese (8). The dotted lines indicate oxygen dependency of nitrification, and the broken lines show couplings of the biological model with the nitrogen cycle model.

terms inside the sixth square bracket) and decompose into dissolved inorganic nitrogen forms (the last term). Fecal pellets sink with a single settling velocity $w_{d}$, whose magnitude varies hyperbolically depending on the detritus concentration as

$$
w_{d}(z)=w_{d}^{*}\left[\frac{D}{R_{d}+D}\right],
$$

where $w_{d}{ }^{*}=8 \mathrm{~m} \mathrm{~d}^{-1}$ is the maximum settling speed, and $R_{d}=0.2 \mathrm{mmol} \mathrm{N} \mathrm{m} \mathrm{m}^{-3}$ is the half saturation constant. Equation (5) specifies higher fall speeds of diatoms and particulate materials when the particles are aggregated at higher concentrations. A similar formalism is also adopted for parameterizing sinking of diatoms with $w_{p}{ }^{*}=1 \mathrm{~m} \mathrm{~d}^{-1}$.

Organic matter decomposition within the oxygenated part of the water column occurs at the rate $\epsilon \mathrm{f}_{n}\left(\mathrm{O}_{2}\right) \mathrm{D}$. The function $\mathrm{f}_{n}\left(\mathrm{O}_{2}\right)$ introduces an oxygen limitation on the efficiency of this process and is expressed by a hyperbolic function

$$
f_{n}\left(O_{2}\right)=\frac{O_{2}}{O_{2}+R_{O}} \text { for } O_{2} \geq 3 \mu M,
$$

with $R_{O}=10 \mu \mathrm{M}$ denoting the half-saturation constant. It implies that the aerobic decomposition rate decreases 
with decreasing oxygen concentrations and vanishes when $\mathrm{O}_{2}<3 \mu \mathrm{M}$ in the water column. This choice of threshold value is consistent with observations from the Black Sea and other oceanic regions [Lipschultz et al., 1990; Yakushev and Neretin, 1997].

When oxygen is depleted in the water column, decomposition of particulate matter occurs anaerobically at a rate $\boldsymbol{\epsilon} \mathrm{f}_{d}\left(\mathrm{O}_{2}\right) \mathrm{D}$ by utilizing nitrate, abundant below the euphotic zone. This process is controlled by the function $\mathrm{f}_{d}\left(\mathrm{O}_{2}\right)$

$$
f_{d}\left(O_{2}\right)=\left[\frac{K_{O}}{K_{O}+O_{2}}\right] \quad \text { for } \quad O_{2}<3 \mu M
$$

which implies that a maximum rate of anaerobic decomposition occurs at zero oxygen concentration and decreases gradually as the oxygen concentration increases. When $\mathrm{O}_{2} \geq 3 \mu \mathrm{M}, \mathrm{f}_{d}\left(\mathrm{O}_{2}\right)$ is set to zero. We take $\mathrm{K}_{O}=$ $2.5 \mu \mathrm{M}$.

In order to avoid additional complexity in the model formulation, we do not invoke a sophisticated DON cycle (for example, as by Anderson et al. [1998]). Phytoplankton exudation and aerobic detritus breakdown constitute the two DON sources, whereas bacterial uptake is the sole loss term in (4b).

Aerobic and anaerobic decomposition of particulate material provide ammonium sources in different parts of the water column (the term inside the first square bracket in (4c). Excretion by plankton groups (the terms inside the second square brackets) constitute another ammonium source in the oxygenated region. The losses include ammonium uptake by phytoplankton (the second term) and its oxidation by oxygen to nitrite under aerobic conditions (the fourth term) as the first step of nitrification. In anaerobic conditions, ammonium is oxidized by particulate manganese available within the suboxic-anoxic interface region (the last term). As we shall see later, this process depletes ammonium in the SOL and prevents its upward transport further into the euphotic zone. Mn oxidation of ammonium therefore completely decouples the subpycnocline ammonium source from the near-surface nitrogen source used for new production. This is a distinctly different feature of the Black Sea from other suboxic basins of the world oceans.

Previous observations [Codispodi et al., 1991; Basturk et al., 1994] indicated that nitrite concentrations in the euphotic zone were always smaller than the other forms of nitrogen. Thus the contribution of nitrite uptake to phytoplankton production is expected to be small. This was further confirmed by our preliminary experiments. Thus the nitrite (4d) involves only oxidation-reduction reactions associated with nitrification and denitrification. In (4d), the first two terms represent the ammonium to nitrite and nitrite to nitrate oxidation reactions in oxygenated waters, respectively. The third and fourth terms, however, represent denitrification under oxygen deficient conditions. The third term models nitrate to nitrite reduction, and the fourth term represents the nitrite reduction to nitrogen gas (the second stage of denitrification). Since nitrogen gas eventually escapes to the atmosphere, this term implies a net nitrogen loss from the system.

The second stage nitrification reaction forms the nitrate source in the model (the first terms in (4e)). The nitrate is lost from the system through its uptake by the phytoplankton (the third term), nitrate reduction (the second term), and $\mathrm{Mn}^{2+}$ oxidation (the fourth term).

\subsection{Redox Model}

The redox model follows Oguz et al. [2000] and is based on a simplified set of oxygen, nitrogen and sulfur reactions, which are catalyzed by the manganese cycle. These reactions are

$$
\begin{gathered}
\mathrm{HS}^{-}+\frac{1}{2} \mathrm{O}_{2}+\mathrm{H}^{+}=\mathrm{S}^{0}+\mathrm{H}_{2} \mathrm{O} \\
2 \mathrm{Mn}^{2+}+\mathrm{O}_{2}+2 \mathrm{H}_{2} \mathrm{O}=2 \mathrm{MnO}_{2}+4 \mathrm{H}^{+} \\
2 \mathrm{NO}_{3}^{-}+5 \mathrm{Mn}^{2+}+4 \mathrm{H}_{2} \mathrm{O}=\mathrm{N}_{2}+5 \mathrm{MnO}_{2}+8 \mathrm{H}^{+} \\
2 \mathrm{NH}_{4}^{+}+3 \mathrm{MnO}_{2}+4 \mathrm{H}^{+}=\mathrm{N}_{2}+3 \mathrm{Mn}^{2+}+6 \mathrm{H}_{2} \mathrm{O} \\
\mathrm{HS}^{-}+\mathrm{MnO}_{2}+3 \mathrm{H}^{+}=\mathrm{S}^{0}+\mathrm{Mn}^{2+}+\mathrm{H}_{2} \mathrm{O} .
\end{gathered}
$$

Thus hydrogen sulfide $\mathrm{HS}^{-}$, elemental sulfur $\mathrm{S}^{0}$, dissolved oxygen $\mathrm{O}_{2}$, dissolved manganese $\mathrm{Mn}^{2+}$, and particulate manganese $\mathrm{MnO}_{2}$ constitute additional elements of the redox model. The kinetics of these reactions are taken to be first order with respect to each of the individual state variables [cf. Oguz et al., 2000]. A schematic view of the redox cycling is shown in Figure $3 \mathrm{~b}$. The set of reactions for each variable of the redox model is given by

$$
\begin{gathered}
\Re\left(O_{2}\right)=\alpha_{0}\left[\sigma_{d} \Phi P_{d}+\sigma_{f} \Phi P_{f}\right]-\alpha_{e} \epsilon f_{n}\left(O_{2}\right) D \\
-\alpha_{2} k_{1} f_{n}\left(O_{2}\right) N H_{4}-\alpha_{3} k_{2} f_{n}\left(O_{2}\right) N O_{2} \\
-\alpha_{5} k_{5}\left(O_{2}\right) H S^{-}-\alpha_{6} k_{6}\left(O_{2}\right) M n^{2+} \\
\Re(H S)=-k_{5} O_{2} H S^{-}-k_{9} \mathrm{HS}^{-} \mathrm{MnO}_{2} \\
\Re(S)=k_{5} \mathrm{O}_{2} \mathrm{HS}^{-}+k_{9} \mathrm{HS}^{-} \mathrm{MnO}_{2}-k_{s} S^{0} \\
\Re(\mathrm{Mn})=\alpha_{8} k_{8} \mathrm{NH}_{4} \mathrm{Mn}^{2+}+k_{9} \mathrm{HS}^{-} \mathrm{MnO}_{2} \\
-k_{6} \mathrm{O}_{2} \mathrm{Mn}^{2+}-k_{7} \mathrm{NO}_{3} \mathrm{Mn}^{2+} \\
\Re\left(\mathrm{MnO}_{2}\right)=k_{6} \mathrm{O}_{2} \mathrm{Mn}^{2+}+k_{7} \mathrm{NO}_{3} \mathrm{Mn}^{2+} \\
-\alpha_{8} k_{8} \mathrm{NH}_{4} \mathrm{Mn}^{2+}-k_{9} \mathrm{HS}^{-} \mathrm{MnO}_{2} .
\end{gathered}
$$

In addition to air-sea exchange (see (15) in section $2.4)$, photosynthetic production in the euphotic zone (the terms in the square parentheses in (13a)) constitutes a source of dissolved oxygen. Oxygen losses arise due to consumption in organic matter decomposition 
(the second term) and oxidation of ammonium and nitrite, hydrogen sulfide, and dissolved manganese (the last four terms).

Hydrogen sulfide is supplied to the water column from the bottom boundary of the model. In the vicinity of the suboxic-anoxic interface zone, it is oxidized first by particulate manganese. The available oxygen resource is also utilized for oxidation of hydrogen sulfide transported upwards in the SOL. These processes are governed by the first and second terms of (13b), respectively. Since elemental sulfur is formed during these oxidation processes, the same kinetic terms appear as the source terms in the sulfur (13c). The last term in the sulfur balance represents bacterially mediated sulfur reduction. The model does not incorporate hydrogen sulfide generation associated with the sulfur reduction.

The reactions driving manganese cycling are given by the terms in (13d) and (13e). Dissolved manganese, transported upwards within the anoxic layer, reacts with nitrate and oxygen (the third and fourth terms) to produce particulate manganese which is then used to oxidize hydrogen sulfide and ammonium (the first two terms). All these reaction terms also appear in (13e) for the particulate manganese balance.

\subsection{Boundary Conditions}

The bottom boundary of the model, $h_{b}$, is $150 \mathrm{~m}$. This roughly corresponds to the base of the permanent pycnocline zone and is situated $\sim 25 \mathrm{~m}$ below the base of the suboxic layer simulated by the model. Unless otherwise specified, the turbulent flux for each state variable is set to zero at the surface and bottom boundaries. In the diatom and detritus equations, this condition is extended to include absence of sinking fluxes. In the most general form, the surface and bottom boundary conditions are specified as

$$
\left[\left(K_{b}+\nu_{b}\right) \frac{\partial F}{\partial z}\right]+w_{b} F=0 \text { at } z=0,-h_{b} .
$$

A justification for the assumption of no export flux of particulate matter from the bottom boundary was given by Oguz et al. [1996, 1999].

In the oxygen equation, the air-sea exchange process is expressed in terms of the "stagnant film" model of Broecker and Peng [1982] as

$$
\left[\left(K_{b}+\nu_{b}\right) \frac{\partial O_{2}}{\partial z}\right]_{z=0}=V_{p}\left[O_{2}^{s a t}-O_{2}(z=0)\right]
$$

where $V_{p}$ is the piston velocity taken as $3 \mathrm{~m} \mathrm{~d}^{-1}$ in our simulations. $\mathrm{O}_{2}{ }^{\text {sat }}$ represents the oxygen saturation concentration computed according to the United Nations Education, Social and Cultural Organization (UNESCO) [1986] formula using the surface temper- ature and salinity values of the physical model at each time step.

$\mathrm{H}_{2} \mathrm{~S}, \mathrm{NH}_{4}{ }^{+}$and $\mathrm{Mn}^{2+}$ concentrations of 25,10 , and $12 \mu \mathrm{M}$ are prescribed, respectively, on the basis of available data at the bottom boundary of the model to drive the sulfur and manganese cycles near the suboxic-anoxic interface zone. The physical model is forced by daily climatological wind stress, the net surface heat flux, and surface salinity. The model prescribes no-stress, noheat, and no-salt flux conditions at the bottom boundary.

\subsection{Numerical Procedure, Initial Conditions, and Transient Adjustment}

Because the model should resolve sharp gradients of oxygen, hydrogen sulfide, and nitrate as well as other gradients in different parts of the water column, a total of 50 vertical levels is introduced with a grid spacing of $\sim 3.0 \mathrm{~m}$. A time step of $5 \mathrm{~min}$ is used in the numerical integration of the system of equations. The vertical discretization scheme is implicit to avoid computational instabilities due to small grid spacing and the relatively large time step. The computational mode of solutions associated with the use of leapfrog time differencing is prevented by applying a time filter at each time step. The finite difference procedure essentially follows the Princeton Ocean Model code.

The physical model is initialized with stably stratified upper ocean temperature and salinity profiles representative of autumn conditions for the interior part of the sea. The integration starts from the first of October which is typically the beginning of mixing season in the water column. The biogeochemical model is initialized with vertically uniform nitrate and ammonium concentrations of 3.5 and $0.5 \mathrm{mmol} \mathrm{m}^{-3}$, respectively, throughout the water column. Oxygen is initially set to $15 \mu \mathrm{M}$ down to $100 \mathrm{~m}$ and zero further below near the lower boundary of the model. Other state variables of the model are initialized with small constant values over the water column. The model therefore does not possess any a priori vertical biogeochemical structure.

First the physical model is integrated for 5 years to achieve a yearly cycle of the upper-layer physical structure. Using these results, the biogeochemical model is then integrated for 4 years to attain an equilibrium solution of the yearly cycles of the biogeochemical fields following a transient adjustment period from the initial conditions. The vertically uniform initial nitrogen structure adjusts itself to changes in the system near the surface and bottom boundaries of the model within a few months after the beginning of the time integration. The entrainment associated with winter cooling tends to build up a uniform nitrate structure within the convectively generated winter mixed layer, whereas nitrogen cycling leads to accumulation of nitrate below 
the seasonal thermocline during the following summer. Near the bottom of the model, denitrification and particulate manganese oxidation gradually erode the initial nitrate structure and form a lower nitracline zone within the first year of integration.

In the oxygenated layer, an initial oxygen concentration of $15 \mu \mathrm{M}$ is taken intentionally to be much smaller than the typical observed values (around 300 $\mu \mathrm{M})$. In fact, this choice was found to be unimportant since the air-sea flux develops the typically observed pattern shortly after the start of model integration. In deeper parts of the water column where the suboxic zone is expected to form, the initial oxygen concentration is higher than that typically found at these depths. Once the biological pump starts functioning, the initial oxygen concentration at these levels decreases owing to oxidation and gradually reaches trace levels in the suboxic zone. The transient adjustment is completed to a large extent within the first year, and the system approaches an equilibrium state within the following 2 years. Specification of higher initial oxygen values prolongs the transient adjustment time but does not alter the vertical oxygen structure of the final state.

A loss of nitrogen during denitrification $\left[\mathrm{k}_{4} \mathrm{f}_{d}\left(\mathrm{O}_{2}\right)\right.$ $\left.\mathrm{NO}_{2}\right]$ and oxidation of dissolved manganese $\left[\alpha_{7} \mathrm{k}_{7} \mathrm{NO}_{3}\right.$ $\mathrm{Mn}^{2+}$ ] occurs within the lower part of the suboxic zone, where nitrate is supplied from the lower nitracline by downward diffusion. Although they are small, such losses are accumulated during the long-term integration and cause a gradual erosion of the nitrate peak, unless there is a compensatory nitrate source. These losses are therefore monitored at each time step, and once the initial temporal adjustment is completed during the first 2 years, an equal amount of nitrate is added to the nitrate equation at the level of its maximum concentration. Within the limitations of the one-dimensional model, this approach was adequate to achieve a conserved system.

The ammonium and hydrogen sulfide equations also possess similar losses expressed by $\mathrm{k}_{8} \mathrm{NH}_{4} \mathrm{MnO}_{2}$ and $\mathrm{k}_{s} \mathrm{~S}^{0}$, respectively. These losses are, however, compensated by the ammonium and sulfide sources prescribed at the lower boundary of the model. With these choices, the model tends to approach to an equilibrium state after two more years of integration, which provides a fully conserved system when integrated over the year and over the water column.

\subsection{Estimation of Parameter Values}

The values of input parameters used in the model simulations (see Tables 1, 2, and 3) were fully explored in our companion papers [cf. Oguz et al., 2000, and Oguz et al., submitted manuscript, 2000]. They were specified from available observations and then optimized by a series of sensitivity experiments. Most of the parameter values given in Table 2 come from measurements performed by the Shirshov Institute of Oceanology, Moscow (E. A. Shushkina, personal communication, 1998). Those given in Table 1 are consistent with other Black Sea studies [Belyeav and Konduforova, 1992; Lebedeva and Shushkina, 1994; Gregoire et al., 1998; Lancelot et al., 2000]. The growth and mortality parameters and the coefficients of food preferences for Aurelia were specified according to Ishii and Bamstedt [1998], Sullivan et al. [1994], and Stoecker et al. [1987], respectively. The measurements carried out by Ward and Kilpatrick [1991], Millero [1991], Tebo [1991], Lewis and Landing [1991], Yao and Millero [1993] and Yakushev and Neretin [1997] were used to deduce the rate constants of various oxidation-reduction reactions of the nitrogen, oxygen, and sulfur cycles (Table 3 ). For

Table 1. Parameters of the Biological Model Used in the Simulations

\begin{tabular}{|c|c|c|}
\hline Parameter & Definition & Value \\
\hline$a$ & photosynthesis efficiency parameter & 0.01 \\
\hline$k_{w}$ & light extinction coefficient for PAR & $0.08 \mathrm{~m}^{-1}$ \\
\hline$k_{c}$ & phytoplankton self-shading coefficient & $0.07 \mathrm{~m}^{2}(\mathrm{mmol} \mathrm{N})^{-1}$ \\
\hline$b_{f}, b_{d}, b_{p}, b_{b}$ & $\begin{array}{l}\text { food preferences of microzooplankton on } \\
\text { flagellate, diatom, detritus, bacteria }\end{array}$ & $0.7,0.2,1.0,1.0$ \\
\hline$a_{f}, a_{d}, a_{z}, a_{p}, a_{b}$ & $\begin{array}{l}\text { food preferences of mesozooplankton on } \\
\text { flagellate, diatom, microzoo, detritus, bacteria }\end{array}$ & $0.2,0.8,0.4,0.7,0.0$ \\
\hline$c_{s}, c_{l}$ & $\begin{array}{l}\text { food preferences of Aurelia } \\
\text { microzoo and mesozooplankton }\end{array}$ & $0.0,0.15$ \\
\hline$\psi$ & ammonium inhibition of nitrate uptake & $3\left(\mathrm{mmol} \mathrm{N} \mathrm{m}^{-3}\right)^{-1}$ \\
\hline$x$ & exudation rate & 0.05 \\
\hline$R_{n}$ & half-saturation constant in nitrate uptake & $0.5 \mathrm{mmol} \mathrm{N} \mathrm{m}^{-3}$ \\
\hline$R_{a}$ & half saturation constant in ammonium uptake & $0.2 \mathrm{mmol} \mathrm{N} \mathrm{m}^{-3}$ \\
\hline$\nu_{b}$ & background kinematic diffusivity for $\mathrm{z} \leq 75 \mathrm{~m}$ & $2 \times 10^{-5} \mathrm{~m}^{2} \mathrm{~s}^{-1}$ \\
\hline$\nu_{b}$ & background kinematic diffusivity for $\mathrm{z}>75 \mathrm{~m}$ & $0.2 \times 10^{-5} \mathrm{~m}^{2} \mathrm{~s}^{-1}$ \\
\hline
\end{tabular}


Table 2. Parameters of the Biological Model Used in the Simulations

\begin{tabular}{cllllllll}
\hline Parameter & \multicolumn{1}{c}{ Definition } & $P_{d}$ & $P_{f}$ & $Z_{s}$ & $Z_{l}$ & $Z_{n}$ & $Z_{m}$ & $B$ \\
\hline & & & & & & & & \\
$Q_{10}$ & $Q_{10}$ parameter in $f(T)$ & 1.2 & 1.2 & 2.0 & 2.0 & 2.0 & 2.2 & 2.5 \\
$\sigma_{i}$ and $r_{\imath}$ & maximum growth rates & 2.9 & 2.0 & 2.0 & 1.3 & 1.0 & $0.15-0.9$ & 3.2 \\
$\lambda_{i}$ & mortality rates & 0.04 & 0.08 & 0.04 & 0.04 & 0.08 & 0.003 & - \\
$\mu_{i}$ & excretion rates & - & - & 0.07 & 0.07 & 0.08 & 0.03 & 0.08 \\
$\gamma_{i}$ & assimilation efficiencies & - & - & 0.75 & 0.75 & 0.80 & 0.80 & - \\
$R_{i}$ & half saturation constants & - & - & 0.5 & 0.4 & 0.5 & 0.7 & 0.75 \\
& & & & & & & & \\
\hline
\end{tabular}

more details on the choice of parameter values, see $O g u z$ et al. [2000], and Oguz et al., (submitted manuscript, 2000).

The ranges of variability and vertical structure of diffusivity and temperature were described previously by Oguz et al., [1996, 1999, 2000] and therefore not repeated here. The temperature at the near-surface levels varies seasonally from minimum values of $\sim 6^{\circ} \mathrm{C}$ within the mixed layer at $\sim 50-75 \mathrm{~m}$ during winter up to $\sim 25^{\circ} \mathrm{C}$ in summer within a shallower mixed layer of less than $15 \mathrm{~m}$. A remnant of cold winter waters resides below the mixed layer and therefore introduces a great deal of temperature stratification within the euphotic zone during the annual warming cycle [see Oguz et al., 1996, Figures 3 and 4] and Oguz et al., [1999, Figure 6a] for the temperature simulations and comparison with observations). The vertical profiles of eddy diffusivity computed by the Mellor-Yamada level 2.5 turbulence parameterization of the physical model exhibit almost 3 orders of magnitude change during the year [see Oguz et al., 1999, Figure 6b]. $\mathrm{K}_{b}$ may be as high as 1000 $\mathrm{cm}^{2} \mathrm{~s}^{-1}$ during the winter period of strong wind and buoyancy induced mixing, compared to values of $1 \mathrm{~cm}^{2}$ $\mathrm{s}^{-1}$ during the summer months. Moreover, a smaller value on the order of $0.01 \mathrm{~cm}^{2} \mathrm{~s}^{-1}$ is suggested in the suboxic zone by microstructure measurements [Gregg and Ozsoy, 1999], as well as by estimates from the Gargett parameterization [Gargett, 1984] and from the oxygen budget computations [Brewer and Spencer, 1974]. Therefore we take the background value of the eddy diffusivity $\nu_{b}=0.2 \mathrm{~cm}^{2} \mathrm{~s}^{-1}$ within the upper $60 \mathrm{~m}$, decreasing linearly to $\nu_{b}=0.02 \mathrm{~cm}^{2} \mathrm{~s}^{-1}$ at $75 \mathrm{~m}$ and retain this value at deeper levels [see Oguz et al., 2000, Figure 2].

\section{Model Results and Discussion}

\subsection{Annual Plankton Cycles and Community Structure}

Results from a specific simulation experiment representing conditions of the Aurelia-dominated Black Sea ecosystem are briefly summarized here and presented more fully by Oguz et al., (submitted manuscript, 2000). A specific data set reported by Shushkina et al. [1983]

Table 3. Parameters of the Nitrogen and Redox Models Used in the Simulations

\begin{tabular}{|c|c|c|}
\hline Parameter & Definition & Value \\
\hline$\epsilon$ & detritus decomposition rates & $0.05 \mathrm{~d}^{-1}$ \\
\hline$\kappa$ & $\begin{array}{l}\text { fraction of detritus remineralization } \\
\text { directly converted to ammonium }\end{array}$ & 0.85 \\
\hline$\alpha_{0}, \alpha_{\epsilon}, \alpha_{2}, \alpha_{3}$ & stoichiometric coefficients & $8.6,0.2,5.3,8.6$ \\
\hline$\alpha_{5}, \alpha_{6}, \alpha_{7}, \alpha_{8}$ & stoichiometric coefficients & $0.5,0.5,0.4,1.5$ \\
\hline$k_{1}$ & rate of ammonium oxidation by $\mathrm{O}_{2}$ & $0.1 \mathrm{~d}^{-1}$ \\
\hline$k_{2}$ & rate of nitrite oxidation by $\mathrm{O}_{2}$ & $0.25 \mathrm{~d}^{-1}$ \\
\hline$k_{3}$ & nitrate reduction rate & $0.05 \mathrm{~d}^{-1}$ \\
\hline$k_{4}$ & nitrite reduction rate & $0.03 \mathrm{~d}^{-1}$ \\
\hline$k_{5}$ & rate of sulfide oxidation by $\mathrm{O}_{2}$ & $0.05 \mu \mathrm{M} \mathrm{d}^{-1}$ \\
\hline$k_{6}$ & rate of manganese oxidation by $\mathrm{O}_{2}$ & $0.1 \mu \mathrm{M} \mathrm{d} \mathrm{d}^{-1}$ \\
\hline$k_{7}$ & rate of manganese oxidation by $\mathrm{NO}_{3}$ & $0.25 \mu \mathrm{M} \mathrm{d}^{-1}$ \\
\hline$k_{8}$ & rate of ammonium oxidation by $\mathrm{MnO}_{2}$ & $1.0 \mu \mathrm{M} \mathrm{d}^{-1}$ \\
\hline$k_{9}$ & rate of sulfide oxidation by $\mathrm{MnO}_{2}$ & $30 \mu \mathrm{M} \mathrm{d}^{-1}$ \\
\hline$k_{s}$ & sulfide reduction rate & $0.01 \mathrm{~d}^{-1}$ \\
\hline$W_{s}^{*}$ & fall speed of manganese particles & $3.0 \mathrm{~m} \mathrm{~d}^{-1}$ \\
\hline
\end{tabular}



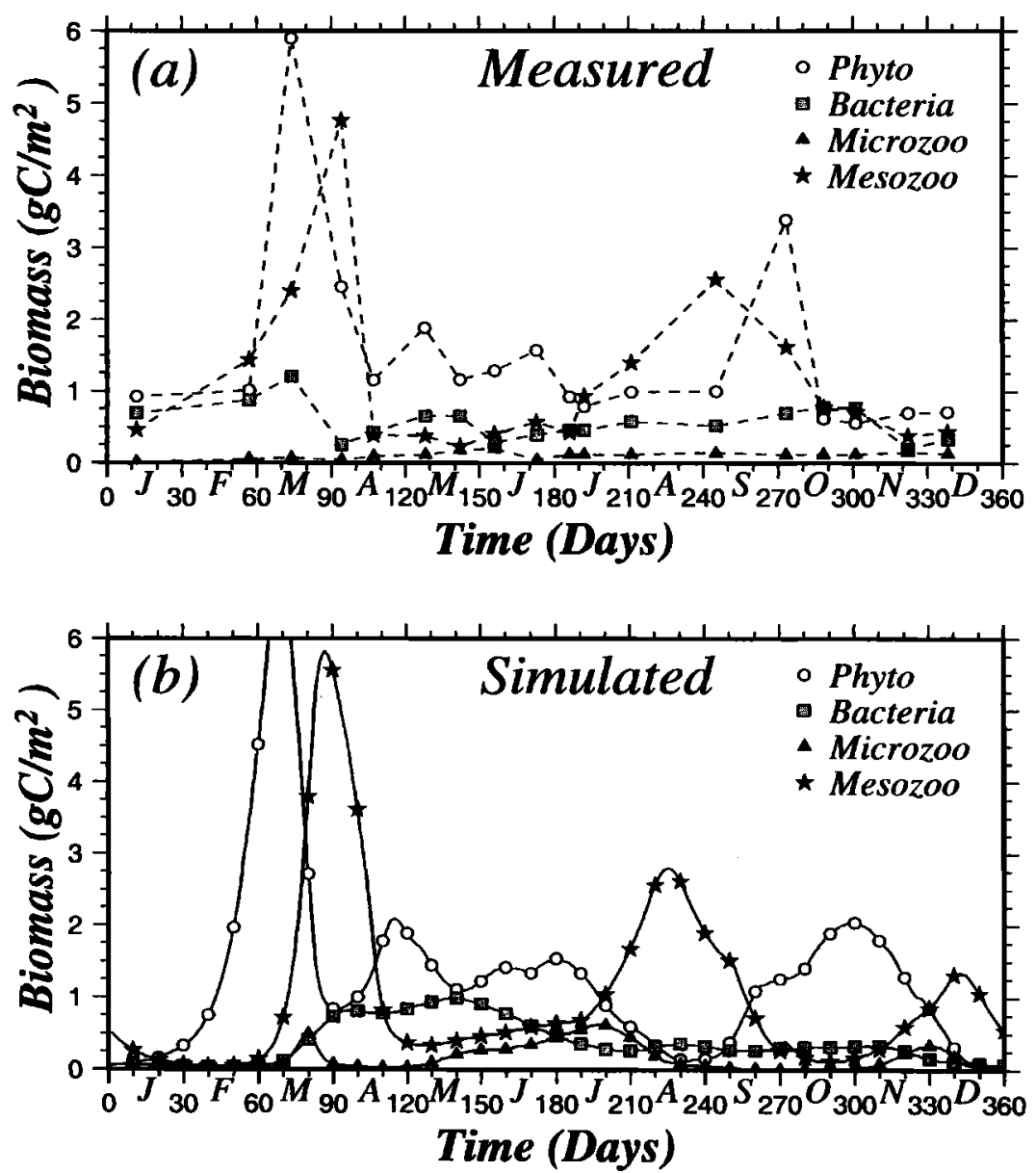

Figure 4. Temporal variations of water column integrated phytoplankton, bacterioplankton, microzooplankton, and mesozooplankton biomass (a) observed at a station off Gelendzhik during 1978 (after Shushkina et al., [1983]) and (b) simulated by the model.

is used to validate simulations of annual phytoplankton, microzooplankton, mesozooplankton and bacterioplankton community structures. The results are computed in the units of mmol $\mathrm{N}$ and then converted to carbon units using the carbon to nitrogen ratio of 8.0 adopted in our earlier models. This ratio is set to 4.0 for Aurelia [Purcell and Kremer, 1983].

The measured versus simulated annual distributions of water column integrated phytoplankton, microzooplankton, mesozooplankton and bacterial biomass are shown in Figures $4 \mathrm{a}$ and $4 \mathrm{~b}$ Figure 4 . One of the most notable features in Figure $4 \mathrm{~b}$ is the presence of successive peaks of phytoplankton and mesozooplankton from March to May associated with prey-predator interactions in the pelagic ecosystem. The strongest phytoplankton bloom event of the year starts by the end of January, intensifies exponentially during February, and reaches its peak value of $\sim 6.0 \mathrm{gC} \mathrm{m}^{-2}$ within the first week of March. It is followed by two additional, longerlasting bloom events during April-July and OctoberNovember with maximum intensities of $\sim 2.0 \mathrm{gC} \mathrm{m}^{-2}$.
The observed timing and intensity of these events (Figure 4a) were reproduced by the model, even though the model was not initialized and forced by data specifically representative of the 1978 conditions. As shown by the water column phytoplankton distribution over the year in our companion paper Oguz et al., (submitted manuscript, 2000), major parts of the second and third bloom events of the year take place within subthermocline depths of the euphotic zone where light availability [cf. Oguz et al., 1996, Figure 7] and nutrient availability (cf. Oguz et al., submitted manuscript, 2000 , Figures $5 \mathrm{a}$ and $5 \mathrm{~b}$ ) were sufficient to promote net phytoplankton growth.

Both the data and model simulation suggest low microzooplankton biomass (less than $0.5 \mathrm{gC} \mathrm{m}^{-2}$ ) throughout the year. This is a consequence of their low growth rate and predation by the mesozooplankton and Aurelia communities. Similarly, the water column integrated bacterioplankton biomass (Figure $4 \mathrm{~b}$ ) is low (typically less than $\sim 0.5 \mathrm{gC} \mathrm{m}^{-2}$ ) during the late autumn and vanishes toward the winter season. Bacterioplankton 


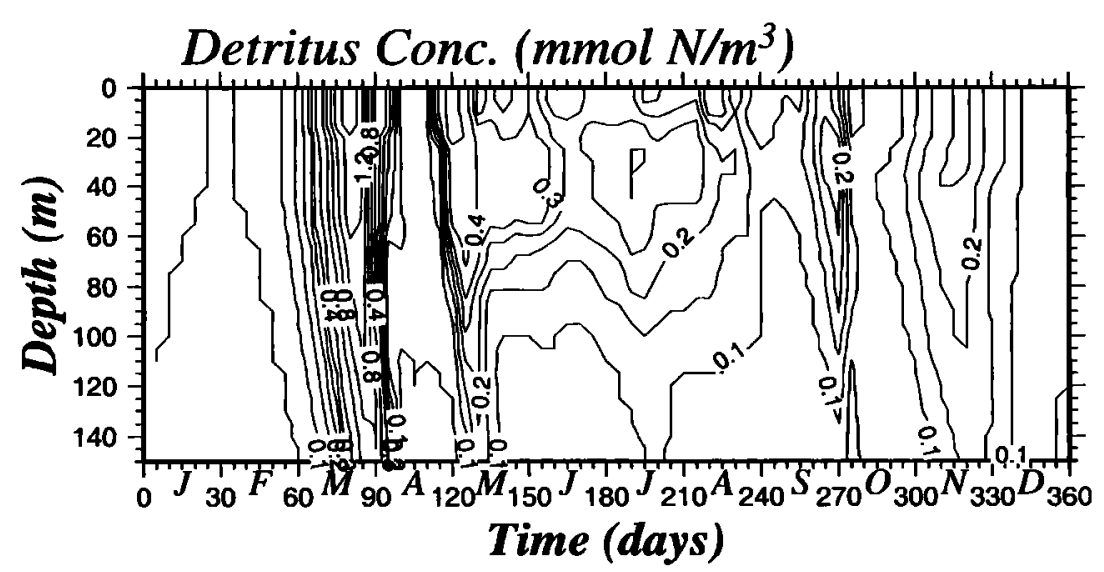

Figure 5. Temporal variations of detrital material (in $\mathrm{mmol} \mathrm{N} \mathrm{m} \mathrm{m}^{-3}$ ) within the water column simulated by the model.

stocks almost double following the March diatom bloom until midsummer. The successive phytoplankton, mesozooplankton, Noctiluca, and Aurelia peaks govern organic matter production and thus the efficiency of nitrogen cycling in the water column throughout the year.

\subsection{Water Column Nitrogen Structure}

The annual distribution of detritus within the water column (Figure 5) follows that of the plankton blooms (Figure 4). Particulate matter is depleted completely during the winter season when there is minimal biological activity. It exhibits a rapid increase in March to maximum concentrations of $\sim 1.4 \mathrm{mmol} \mathrm{N} \mathrm{m}{ }^{-3}$ following the maximum annual phytoplankton and mesozooplankton production (see Figure 4b). These blooms are, however, rapidly remineralized and converted to ammonium and nitrate which are then made available for regenerated production in the subsequent months. The signature of regenerated production is evident in the detritus distribution shown in Figure 5 as transient increases in concentration during the May-June and September-October periods. The detritus distribution tends to decrease with depth indicating that particulate matter is remineralized preferentially within the oxygenated part of the water column (see Figure 10 for oxygen distributions). Anaerobic decomposition remineralizes the rest of the detrital material sinking toward the deeper part of the water column. Recall that there is no export from the base of the model as implied by our choice of boundary conditions (see (14)).

Vertical profiles of nitrate concentration are plotted at selected times of the year in Figure 6. Prior to the February-March phytoplankton bloom, nitrate concentrations increase gradually by more than $2 \mathrm{mmol} \mathrm{m}^{-3}$ within the upper $50 \mathrm{~m}$ (see the end of December and January profiles in Figure). The summer mixed layer concentrations, however, do not exceed $0.1 \mathrm{mmol} \mathrm{m}^{-3}$ due to lack of supply from subsurface levels across the strong seasonal thermocline/pycnocline located at $\sim 15$ $m$ depth. In the region below the seasonal thermocline, a layer of vertically uniform nitrate concentrations is evident to $50 \mathrm{~m}$ depth. Starting after the bloom period in March, the May and August profiles (see nitrate distribution given by Oguz et al., submitted manuscript, 2000 , Figure 5) indicate a gradual build-up of nitrate in this zone as a consequence of the increased biological activity and subsequent nitrogen recycling. Nitrate accumulated in this region supports subsurface phytoplankton production during the summer (cf. Oguz et al., submitted manuscript, 2000, Figures 5a-5c). Further below, the nitrate profiles possess a linear increase up to a distinct maximum of about $7 \mathrm{mmol} \mathrm{m} \mathrm{m}^{-3}$ at around $70 \mathrm{~m}$. The peak is broader and stronger during the autumn and winter corresponding to a more active nitrogen recycling phase following the spring and summer phytoplankton blooms. Thus different slopes of the

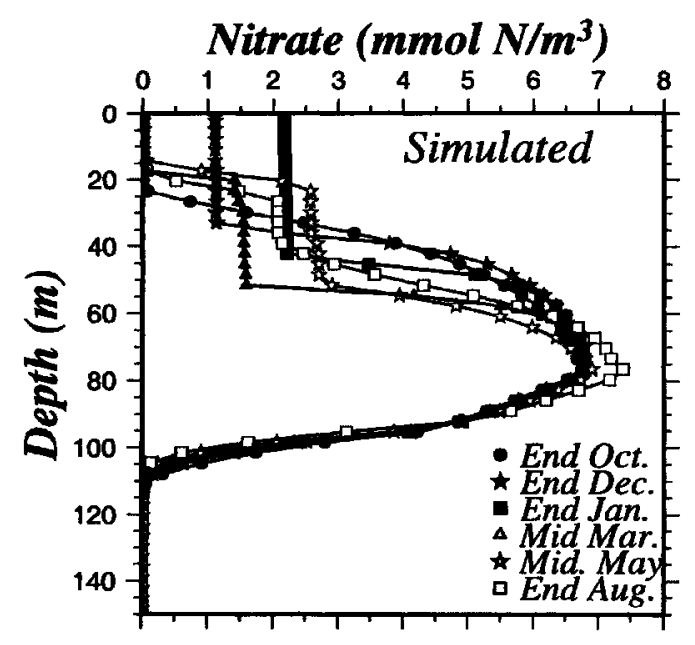

Figure 6. The model simulated daily averaged vertical nitrate profiles (in mmol $\mathrm{N} \mathrm{m}^{-3}$ ) versus depth (m) at selected times of the year. 

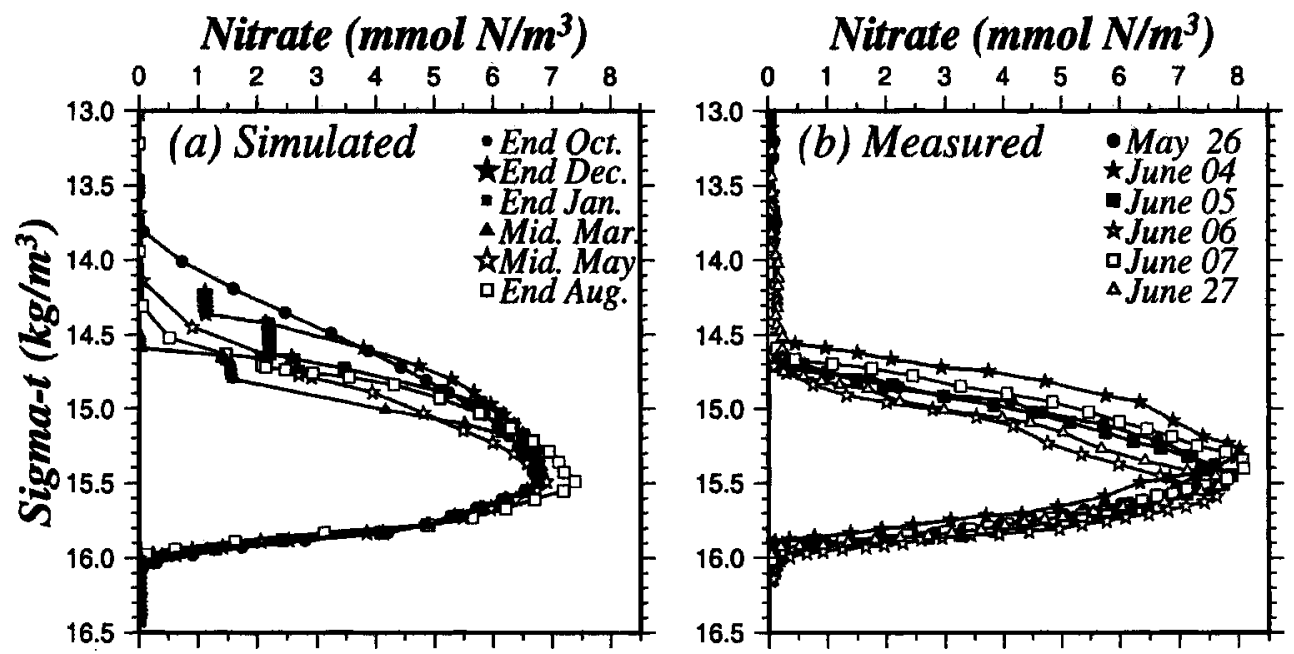

Figure 7. (a) The model simulated, and (b) observed nitrate profiles versus sigma-t $\left(\mathrm{kg} \mathrm{m}^{-3}\right)$ at selected times of the year. The observed profiles were obtained by the R/V Knorr surveys in the Black Sea during summer 1988. The concentrations are expressed in units of mmol $\mathrm{N} \mathrm{m}^{-3}$.

nitracline signify different phases of nitrogen cycling in the water column during the year.

The structure below the level of the nitrate maximum, however, remains uniform throughout the year. This zone is characterized by two different types of nitrate variation. The layer immediately below the peak (from 75 to $95 \mathrm{~m}$ depths) has a relatively larger slope and is followed by much steeper variations (from 95 to $105 \mathrm{~m}$ depths) before nitrate concentrations vanish around $110 \mathrm{~m}$ depth. The balance of ecological processes tends to favor nitrate production within the upper $75 \mathrm{~m}$. The subsequent $35 \mathrm{~m}$. zone represents a layer of continuous nitrate depletion due to consumption during denitrification and oxidation of particulate manganese. In the steady state perpetual year of the model system, the loss is compensated by a downward diffusive nitrate flux.

Considering the fact that the upper layer water column of the Black Sea has a very strong density stratification and that chemical properties are distributed almost uniformly along isopycnal surfaces, it is customary to express vertical variations of biogeochemical properties using density as the vertical coordinate. When nitrate profiles are plotted against density (Figure 7a), the position of the subsurface nitrate peak coincides approximately with the 15.5 sigma-t level. This is generally supported by observations [Tugrul et al., 1992; Saydam et al., 1993; Buesseler et al., 1994; Basturk et al., 1994 and others], although six repeated casts at 42 $50^{\circ} \mathrm{N}$ and $3200^{\circ} \mathrm{E}$ during the 1 month period of the $\mathrm{R} / \mathrm{V}$ Knorr surveys suggest some degree of variability of the peak position between the 15.3 and 15.6 sigma-t levels (Figure 7b). Furthermore, this particular data set provides maximum nitrate values of $\sim 8.0 \mathrm{mmol} \mathrm{m} \mathrm{m}^{-3}$, almost $1 \mathrm{mmol} \mathrm{m}^{-3}$ higher than the value in our simulations. Other data sets indicate regional as well as year to year variability of the nitrate maximum in the

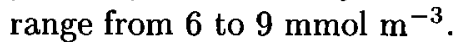

It will be shown section 3.3 that position of the nitrate maximum is intimately related to the location of onset of trace level oxygen concentrations as they control the lower limit of nitrification in the water column. Nitrate concentrations decrease uniformly to their trace values around the 16.0 sigma-t level, which is located roughly $35 \mathrm{~m}$ below the the nitrate maximum (Figure 6). A similar trend can also be seen in the observed profiles (Figure 7b). In addition, the presence of a nitrate depleted zone from the surface to $\sigma_{t} \sim 14.5 \mathrm{~kg} \mathrm{~m}^{-3}$, and subsequent variations up to the nitrate maximum seen in the May and August profiles agree favorably with the observations shown in Figure $7 \mathrm{~b}$.

A set of ammonium profiles computed by the model is shown in Figure 8a, (see Oguz et al., submitted manuscript, 2000, Figure 5c for the annual water column distribution). The summer period is characterized by depleted ammonium stocks within the mixed layer, followed by peak concentrations on the order of 0.2 $0.4 \mathrm{mmol} \mathrm{m} \mathrm{m}^{-3}$ around the base of the euphotic zone. These elevated subthermocline ammonium concentrations arise due to inputs from excretion and aerobic organic matter decomposition (compare (4c)) following subsurface plankton production in summer (cf. Oguz et al., submitted manuscript, 2000, Figure 5a). During the less productive winter months after the autumn phytoplankton bloom (as depicted in Fig. 8a by the December profile), the ammonium peak is eroded to a large extent as it is oxidized to nitrate. At deeper levels, all the ammonium profiles exhibit consistently a linear trend of 

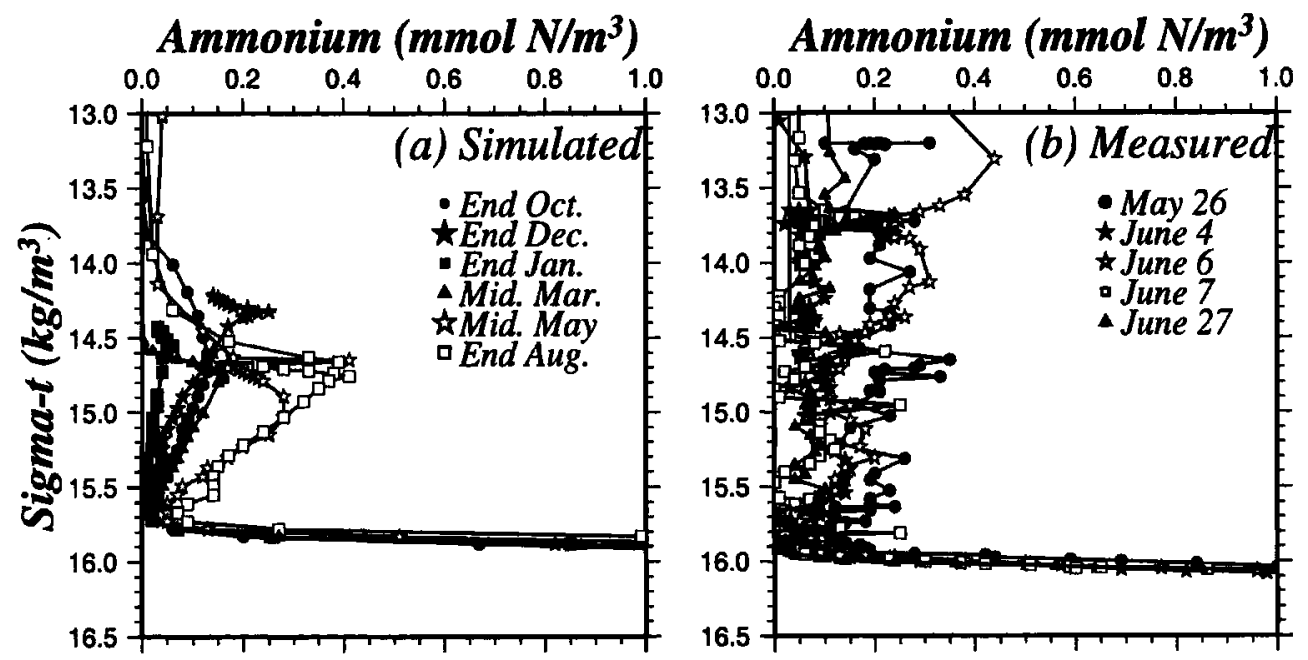

Figure 8. (a) The model simulated daily averaged ammonium profiles versus sigma-t $\left(\mathrm{kg} \mathrm{m}^{-3}\right)$ at selected times of the year, (b) the observed ammonium profiles versus sigma-t $\left(\mathrm{kg} \mathrm{m}^{-3}\right)$ obtained by the R/V Knorr surveys in the Black Sea during summer 1988. The concentrations are expressed in units of $\mathrm{mmol} \mathrm{N} \mathrm{m}^{-3}$.

decrease toward trace concentrations at $\sigma_{t} \sim 15.7 \mathrm{~kg}$ $\mathrm{m}^{-3}$. This position roughly corresponds to the base of a narrow zone of relatively high-nitrate concentrations immediately below the nitrate peak and to the level of low dissolved oxygen concentrations $\sim 3 \mu \mathrm{M}$ (see (10a)). The ammonium concentrations increase sharply below this level, reaching at the values of $1 \mathrm{mmol} \mathrm{m}^{-3}$ near $\sigma_{t} \sim 16.0 \mathrm{~kg} \mathrm{~m}^{-3}$, and its prescribed boundary value of $10 \mathrm{mmol} \mathrm{m}^{-3}$ at $\sigma_{t} \sim 16.5 \mathrm{~kg} \mathrm{~m}^{-3}$.

The vertical nitrite structure computed by the model is similar to ammonium and exhibits two distinct maxima (Figure 9a). The first peak is located within the oxygenated part of the water column at the same depths as ammonium since nitrite is an intermediate product of the $\mathrm{NH}_{4}{ }^{+}$to $\mathrm{NO}_{3}{ }^{-}$oxidation. Presence of such peaks near the base of the euphotic zone with concentrations of $\sim 0.2 \mathrm{mmol} \mathrm{m}^{-3}$ are reported by Codispoti et al., [1991] and Basturk et al., [1994], as shown in Figure $9 \mathrm{~b}$. The second peak, with concentrations of $\sim 0.5 \mathrm{mmol} \mathrm{m}^{-3}$, is developed within the suboxic layer around $\sigma_{t} \sim 15.90 \mathrm{~kg} \mathrm{~m}^{-3}$ and is associated with nitrate reduction. This peak therefore marks the denitrification zone which corresponds in our model to the depths with oxygen concentrations less than $3 \mu \mathrm{M}$. Its location and magnitude are consistent with observations (Figure $9 \mathrm{~b}$ ).

In contrast to nitrite, a series of successive ammo-
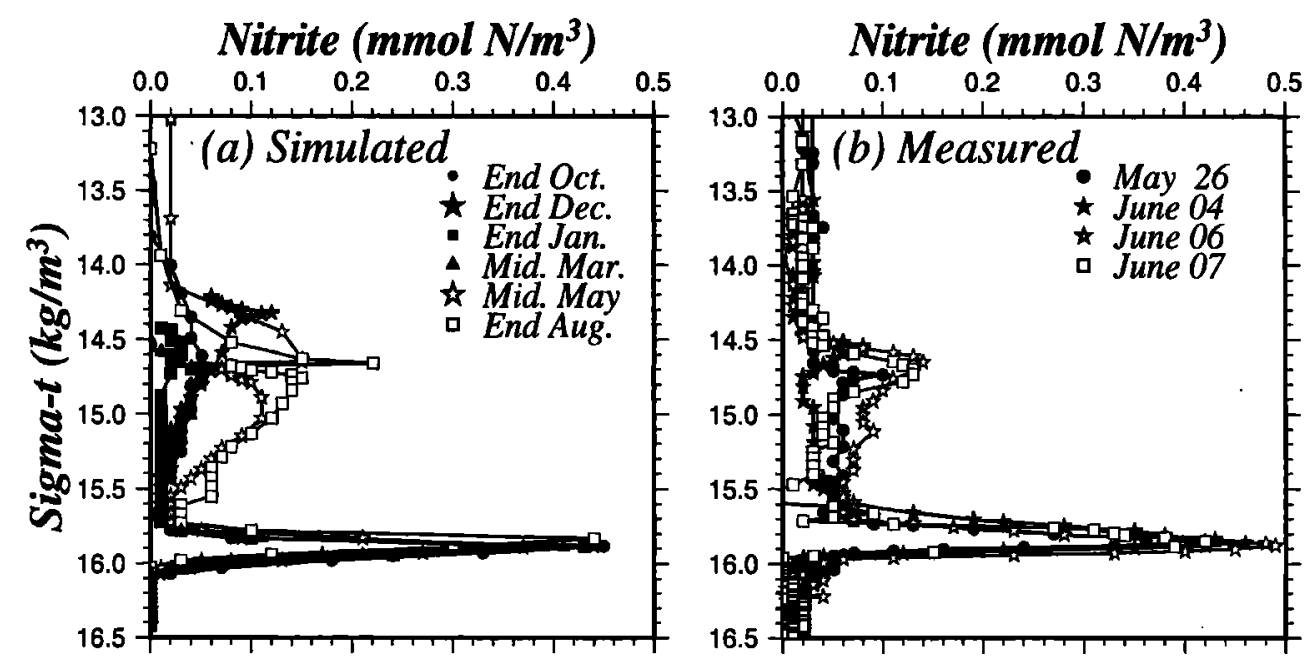

Figure 9. (a) The model simulated daily averaged nitrite profiles versus sigma-t $\left(\mathrm{kg} \mathrm{m}^{-3}\right)$ at selected times of the year, (b) the observed nitrite profiles versus sigma-t $\left(\mathrm{kg} \mathrm{m}^{-3}\right)$ obtained by the R/V Knorr surveys in the Black Sea during summer 1988. The concentrations are expressed in units of $\mathrm{mmol} \mathrm{N} \mathrm{m}^{-3}$. 


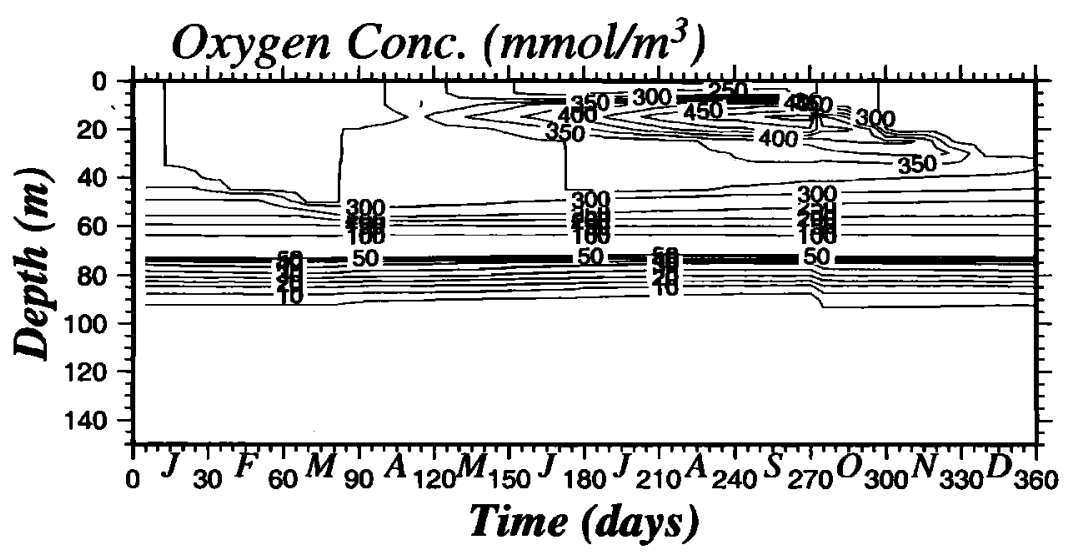

Figure 10. Temporal variations of dissolved oxygen within the water column simulated by the model. Contours are drawn at intervals of $50 \mathrm{mmol} \mathrm{m}^{-3}$ for concentrations greater than $50 \mathrm{mmol}$ $\mathrm{m}^{-3}$ and of $10 \mathrm{mmol} \mathrm{m}^{-3}$ otherwise.

nium profiles (Figure 8b) carried out in the Knorr 1988 surveys reveal more complicated and noisy structure, which does not at all resemble the form of our simulated profiles. A closer inspection, however, provides an indication of several peaks in different profiles confined within the oxygenated part of the water column (i.e., at depths less than $\sigma_{t} \sim 15.0 \mathrm{~kg} \mathrm{~m}^{-3}$ ). Ammonium within the suboxic layer also has complicated structure and varies from one sample to another. Ammonium transported upward from the deep pool seems to decrease to trace concentrations at some depth between the $\sigma_{t} \sim 15.7$ and $15.9 \mathrm{~kg} \mathrm{~m}^{-3}$ levels in different profiles. Some profiles do not even reveal an ammonium depleted zone but instead show concentrations greater than $\sim 0.2 \mathrm{mmol} \mathrm{m}{ }^{-3}$. The source of such variability in the ammonium measurements, contrary to that observed in other variables, could be partially due to the complexity of the redox reactions in this zone. Measurement errors may also contribute to noise in Figure $8 \mathrm{~b}$.

\subsection{Water Column Oxygen Structure}

The euphotic layer oxygen concentration undergoes pronounced seasonal variations within a broad range of values from $\sim 250$ to $450 \mu \mathrm{M}$ (Figure 10). The period from the beginning of January until mid-March exhibits vertically uniform mixed layer concentrations of $\sim 325 \mu \mathrm{M}$, ventilating the upper $50 \mathrm{~m}$ of the water column as a result of convective overturning. The role of atmospheric oxygen input in the ventilation process depends upon the excess of saturated oxygen concentrations over the surface oxygen and the value of the piston velocity (see (15)). The maximum contribution of oxygen saturation is realized toward the end of February during the period of coolest mixed layer temperatures (see Oguz et al., [1999]), coinciding with the maximum and deepest winter oxygen concentrations during the year. After March, with the initiation of the warming season, the surface oxygen flux given by (15) drives an efflux of oxygen to the atmosphere. The signature of this loss in Figure 10 is the reduction of oxygen concentrations to $250 \mu \mathrm{M}$ within the uppermost $10 \mathrm{~m}$ during the spring and summer months. A subsequent linear trend of increase across the seasonal thermocline links lower surface oxygen concentrations to those of relatively higher subthermocline concentrations. Depending on the strength of summer phytoplankton productivity, the sub-thermocline concentrations vary from $350 \mu \mathrm{M}$ in mid-May to $450 \mu \mathrm{M}$ during July-September, as further quantified by the distribution of photosynthetic oxygen production (Figure 11a). Typical oxygen profiles observed during the winter and summer months (Figures 12a and 12b) are similar to our simulations in terms of both the form of vertical profile and the range of oxygen concentrations. The winter profiles exhibit vertically homogeneous oxygen concentrations of around $350 \mu \mathrm{M}$ as predicted by the model. The summer profiles also resemble those computed by our model except with $\sim 50 \mu \mathrm{M}$ lower peak concentration values.

No major seasonal variations take place in oxygen below $50 \mathrm{~m}$ depth (Figure 10). Irrespective of the season, the oxygen concentration decreases almost linearly within the oxycline zone to $\sim 50 \mu \mathrm{M}$ at $75 \mathrm{~m}$, to $10 \mu \mathrm{M}$ at $90 \mathrm{~m}$, and finally vanishes at about $95 \mathrm{~m}$. Remineralization appears to be the major sink for oxygen at these levels, exceeding the oxygen consumption due to nitrification by almost an order of magnitude (Figures $11 \mathrm{~b}$ and 11c).

The simulated and observed variations within the oxycline and the suboxic zone are shown in further detail in Figures 13a and 13b. The computed profiles suggest linear variations within the oxycline from concentrations of $\sim 100 \mu \mathrm{M}$ at $\sigma_{t} \sim 15.3 \mathrm{~kg} \mathrm{~m}^{-3}$ to $\sim 10 \mu \mathrm{M}$ at $\sigma_{t} \sim 15.7 \mathrm{~kg} \mathrm{~m}^{-3}$ without any seasonal variations (Fig- 

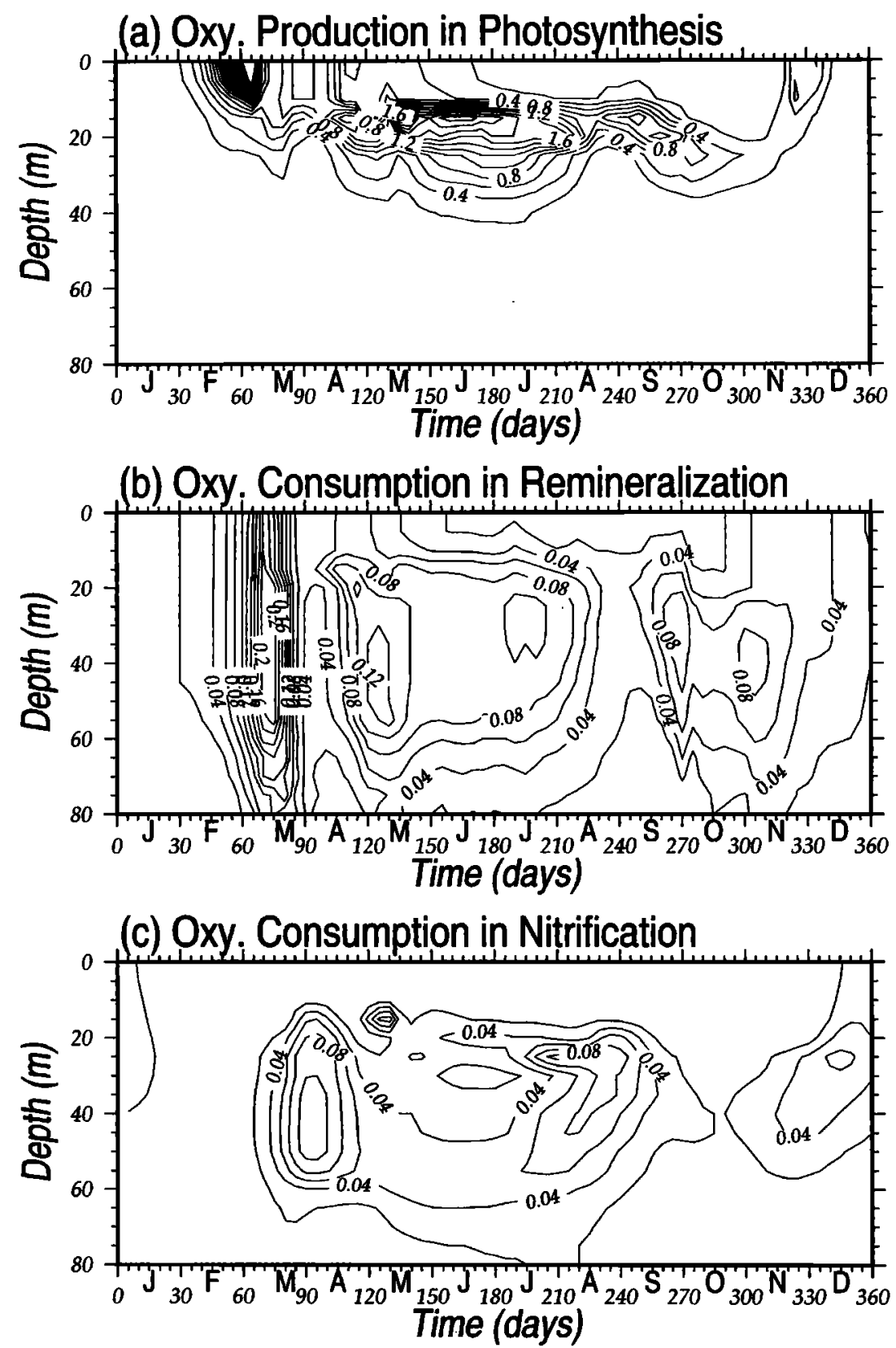

Figure 11. Temporal variations of the (a) photosynthetic oxygen production rate, (b) oxygen consumption rate during remineralization, and (c) oxygen consumption rate during nitrification computed by the model. The concentrations are expressed in units of mmol m $\mathrm{m}^{-3} \mathrm{~d}^{-1}$. Contours are drawn at intervals of 0.2 in Figure 11a, and of 0.02 in Figures $11 \mathrm{~b}$ and 11c.

ure 13a). Within the suboxic layer, oxygen concentrations vanish around $\sigma_{t} \sim 15.9 \mathrm{~kg} \mathrm{~m}^{-3}$, which is located $\sim 7 \mathrm{~m}$ (or equivalently $\Delta \sigma_{t} \sim 0.1 \mathrm{~kg} \mathrm{~m}^{-3}$ ) above the position of the nitrate depletion. When compared with the observed profiles in Figure 13b, the position and slope of the simulated oxycline zone as well as its structure within the suboxic layer lie within the range of observed variation. We note in Figure 13b that the June and July 1988 profiles differ from each other, even though their structures are all consistent with the definition of the suboxic layer. We expect that eddy-induced variability associated with the complex, mesoscale-dominated circulation system could be a mechanism for generating short-term changes in the structure of the suboxic zone oxygen profile. Our sensitivity experiments suggested that slightly different choices of the vertical eddy diffusivity can generate such variations.

Because the $\mathrm{H}_{2} \mathrm{~S}$ layer is located only $\sim 100 \mathrm{~m}$ below 

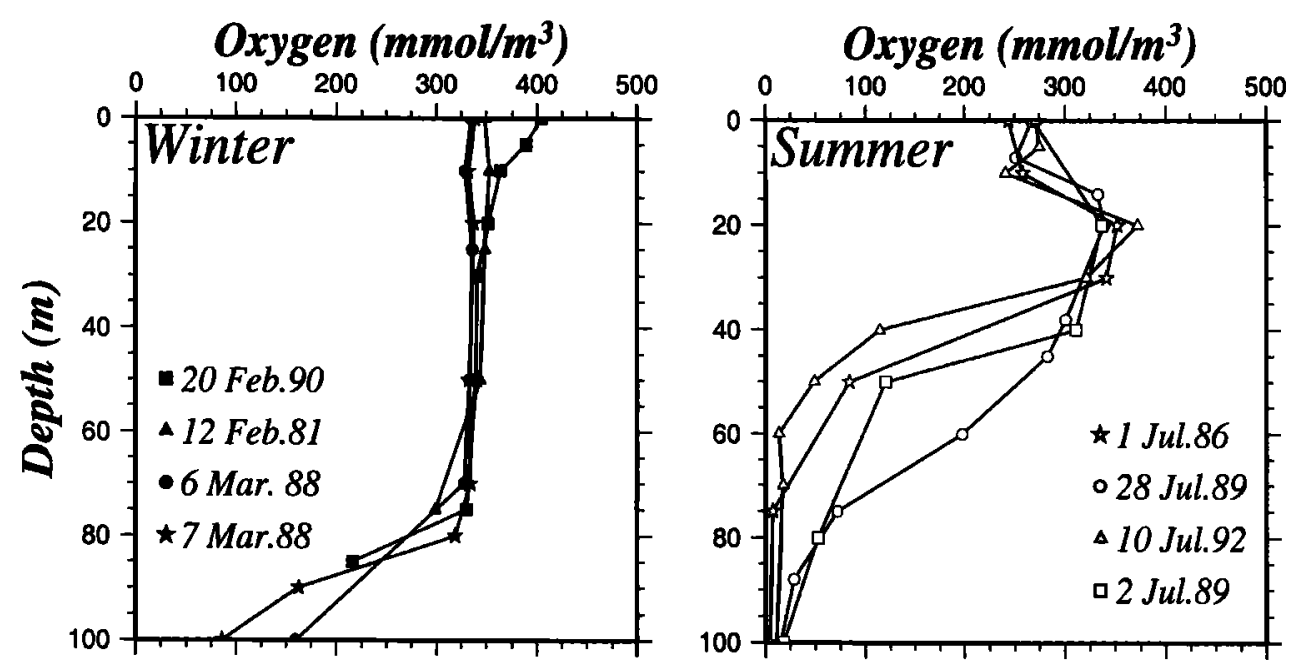

Figure 12. Typical observed oxygen profiles measured during (a) winter and (b) summer months. The data are taken from the Black Sea database system with permission from the developers.

the surface in most parts of the Black Sea, the possible vertical extent of ventilation of the upper layer water column is a critically important issue. Apart from lateral ventilation events across the shelf break [Basturk et al., 1998], one possible ventilation mechanism is the convective overturning process following intense winter atmospheric cooling episodes. Although this process in general takes place intermittently in the form of strong cold air outbreaks, we investigated its role in this model by specifying a smoothly varying, continuous, but stronger cooling over the winter season. Then, using the equilibrium solution of the experiment described above as the initial condition, we forced the model for one additional year with a three- fold stronger climatological heat flux (i.e., cooling) during the December-February period. Accordingly, the monthly averaged heat fluxes applied in this period were taken to be 450,390 , and $210 \mathrm{~W} \mathrm{~m}^{-2}$. When compared with typical climatological conditions, the minimum winter mixed layer temperature is reduced to $2^{\circ} \mathrm{C}$ which is $\sim 4.5^{\circ} \mathrm{C}$ lower than that of the standard run [see Oguz et al., 1999, Figure 6a]. Because of the presence of very strong upper layer stratification, this stronger, season-long cooling causes only an $\sim 0.5 \mathrm{~kg} \mathrm{~m}^{-3}$ increase in the mixed layer density. The corresponding mixed layer deepening is therefore insignificant and not more than $\sim 10-15 \mathrm{~m}$ (not shown). Thus it appears that the strong stability of the water column hardly allows any
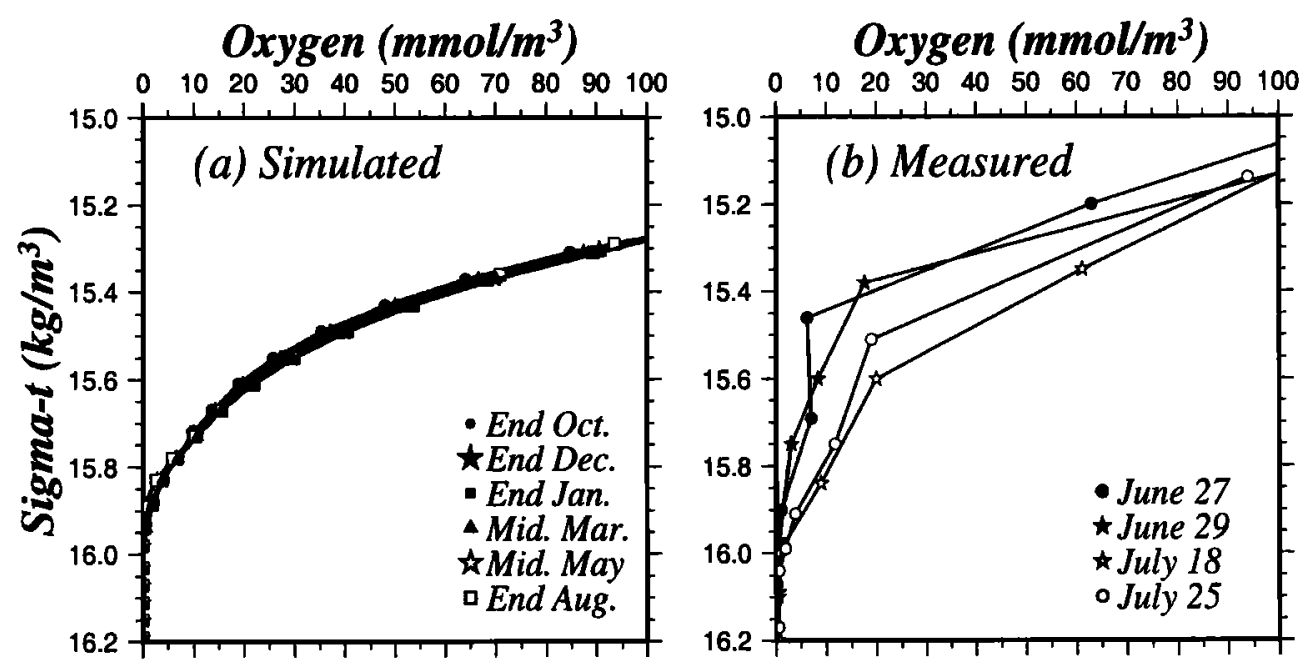

Figure 13. (a) The model simulated daily averaged dissolved oxygen profiles versus sigma-t $(\mathrm{kg}$ $\mathrm{m}^{-3}$ ) within the oxycline and suboxic layers of the water column at selected times of the year, (b) the observed dissolved oxygen profiles versus sigma-t obtained by the R/V Knorr surveys in the Black Sea during summer 1988. 


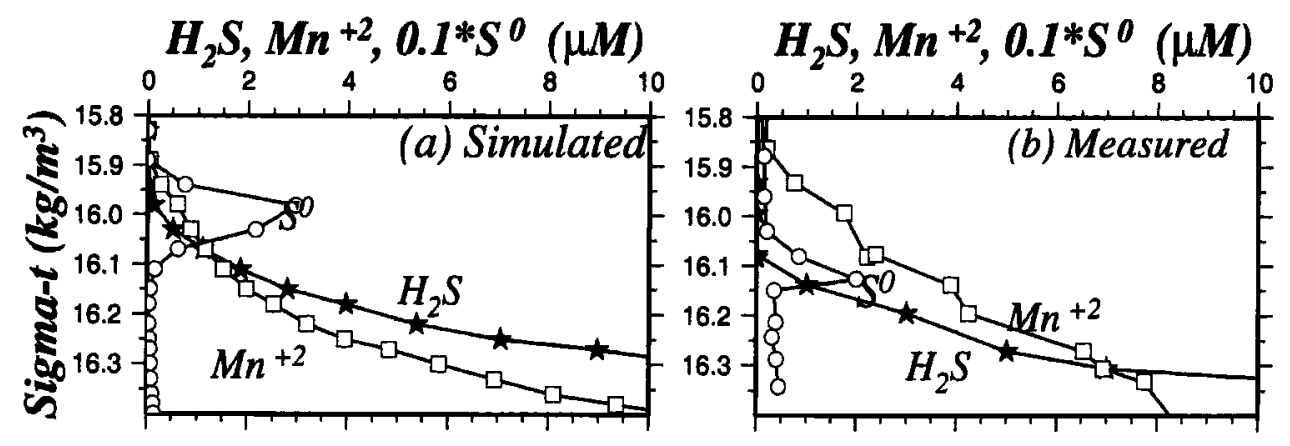

Figure 14. (a) The model simulated annual mean profiles of hydrogen sulfide, elemental sulfur, and dissolved manganese versus sigma-t $\left(\mathrm{kg} \mathrm{m}^{-3}\right)$ in the vicinity of the anoxic interface zone, (b) the corresponding profiles obtained by the R/V Knorr surveys in the Black Sea during summer 1988.

seasonal variation of the oxygen below $60-70 \mathrm{~m}$ due to atmospheric ventilation. A similar limited vertical extent of ventilation can also be inferred from the observed winter profiles shown in Figure 12a.

\subsection{Suboxic-Anoxic Interface Structure}

The vertical profiles of hydrogen sulfide, elemental sulfur, and dissolved manganese computed by the model and the corresponding profiles observed during the $\mathrm{R} / \mathrm{V}$ Knorr surveys are shown respectively in Figures 14a and 14b. The computed profiles are plotted only for the annual mean values since the suboxic-anoxic interface zone structure is unaffected by seasonally varying euphotic and oxycline/nitracline processes and therefore does not possess any significant temporal variability. One important feature noted in Figure 14a is reduction of hydrogen sulfide concentrations to trace values at around the $\sigma_{t} \sim 15.95 \mathrm{~kg} \mathrm{~m}^{-3}$ level whereas oxygen vanishes at slightly shallower depths of $\sigma_{t} \sim 15.85 \mathrm{~kg}$ $\mathrm{m}^{-3}$ (see Figure 13a). The level of vanishing hydrogen sulfide, however, does coincide with that of nitrate (see Figsures 6 and 7), implying its crucial role in hydrogen sulfide oxidation. As described in section 2.3, nitrate oxidizes dissolved manganese as the latter diffuses upward from deeper levels. This reaction produces particulate manganese, which then oxidizes hydrogen sulfide and generates, as a by-product, dissolved manganese which contributes to maintaining the redox processes in this zone. The availability of dissolved manganese through diffusion from deeper levels as well as local production can be inferred in Figure 14a by its slightly higher values, compared with those of sulfide near the interface zone. Elemental sulfur is also produced as a by-product in these processes. The sulfur peak shown in Figure 14a thus identifies the vertical extent of these redox reactions.

Observations (Figure 14b) support our simulations fairly well and point to the fact that the redox reactions formulated in our model can describe the main features of the interface structure. The simulated and observed profiles, however, indicate some differences too. The most notable is the presence of slightly higher observed dissolved manganese concentrations near the base of the suboxic zone. Availability of excess manganese leads to a higher rate of sulfide oxidation and consequently sulfide depletion at somewhat lower levels. This might explain the slight differences between the locations of simulated and observed trace sulfide concentrations in Figures $14 \mathrm{a}$ and $14 \mathrm{~b}$. For more details on the performance of the redox cycling model, we refer to Oguz et al. [2000].

\section{Summary and Conclusions}

The upper layer biogeochemical structure within the interior Black Sea is simulated using a one-dimensional, time-dependent, vertically resolved physical biogeochemical model applied to interior Black Sea conditions. The physical model uses a sophisticated mixed layer dynamic involving a level 2.5 turbulence closure and is coupled with the biogeochemical model by prognostically computed water column eddy diffusivity and temperature at each time step. The pelagic foodweb is represented by complex prey-predator interactions between different phytoplankton and zooplankton groups. In the model pelagic foodweb, the gelatinous carnivorous jellyfish Aurelia aurita and the opportunistic dinoflagellate Noctiluca scintillans control functioning of the eutrophied ecosystem of the Black Sea. Biogeochemical transformations between organic and inorganic forms of nitrogen are introduced through the remineralizationammonification-nitrification-denitrification chain of the nitrogen cycle and are coupled with the pelagic foodweb model. These processes are finally linked to a series of oxidation-reduction reactions controlling the structure and dynamics of the suboxic-anoxic transition zone. The redox model includes anaerobic oxidation of hydrogen sulfide through a series of reactions catalyzed by dissolved and particulate manganese. Dissolved oxy- 
gen is introduced as an additional prognostic variable for more realistic representation of aerobic remineralization and nitrification.

The results presented in this paper show the capability of the model to simulate basic characteristic features of the upper layer biogeochemical structure for the Black Sea. The simulations indicate an almost continuous particulate organic material production over the annual cycle and nitrogen cycling associated with year-long biological activity. The biogeochemical pump maintains a particular nitrate structure over the year, characterized by a well-pronounced nitracline near the base of euphotic zone and a subsequent subsurface maximum. The model demonstrates that oxygen consumption during particle remineralization and nitrification, together with limited ventilation of subsurface waters, are the two main factors governing the form of the nitrate profile. Oxygen, generated photosynthetically and by air-sea interactions, is consumed immediately within approximately the upper $75 \mathrm{~m}$ of the water column. The layer below is not ventilated at all due to the presence of a very strong density stratification across the permanent pycnocline. The most dynamic biogeochemical processes are therefore restricted to the upper $75 \mathrm{~m}$ depth of the water column.

Biogeochemical processes in deeper levels possess a very different character. In the oxygen-deficient part of the water column, organic matter decomposition occurs via denitrification by consuming subsurface nitrogen resources. This causes a continual loss of nitrate from the system, evident from the strong reduction in subsurface concentrations within $\sim 20-30 \mathrm{~m}$ below the level of the nitrate peak. The second important nitrate loss in this zone is due to its consumption through oxidation of hydrogen sulfide and ammonium transported upward from deeper levels. These losses are compensated by downward diffusive transport from the upper levels. The result of these processes is formation of an oxygen deficient, nonsulfidic layer with strong nitrate variations and without any appreciable ammonium concentration. The model thus provides quantitative evidence of the quasi-permanent suboxic layer.

The annual plankton cycle measured biweekly at a station during 1978 seems to be a robust example of the ecosystem of the 1980s dominated by gelatinous predators. A similar distribution was also provided by the mean CZCS chlorophyll distribution in the 19801985 period [Nezlin et al., 1999] as well as other in situ measurements [Shushkina et al., 1998; Vedernikov and Demidov, 1993, 1997; Yilmaz et al., 1998]. This plankton structure was modified to some extent after 1989 owing to additional top-down pressure introduced by the population outburst of Mnemiopsis [Shushkina et al., 1998; Oguz et al., submitted manuscript, 2000]. In contrast, measurements performed during 1980s and 1990s on a regular basis [Basturk et al., 1994,
1997, 1998; Konovalov et al., 1999] suggested quasistability of the subsurface nitrogen structure and of the suboxic layer over the last 15 years. The long-term, anthropogenically driven increase in subsurface nitrate concentrations since the 1960s was a critical factor for maintaining stability of the nitracline and suboxic layer on a decadal timescale and thus preventing the shoaling of the hydrogen sulfide interface. Owing to very high stratification within the upper $100 \mathrm{~m}$, the biogeochemical properties are almost uniformly distributed along density surfaces and thus possess a great deal of uniformity when the results are interpreted in terms of density as a vertical coordinate, rather than depth. It is therefore reasonable to say that the results presented here represent fairly robust biogeochemical characteristics of the Black Sea and are valid for the entire basin except the shelf region along the western coast.

Acknowledgments. This work is a contribution to the Black Sea-ODBMS Project sponsored by the NATO Science for Peace Program. It is supported in part by the NSF Grant OCE-9906656 to T. Oguz and P. Malanotte-Rizzoli and OCE-9908092 to H. W. Ducklow. T. Oguz also acknowledges NATO Linkage Grant EST.CLG975821, which enabled him to interact with various scientists from other Black Sea countries. T. Oguz thanks J.W. Murray, M.E. Vinogradov and E.A. Shushlina for stimulating discussions. The comments by the anonymous reviewers were helpful to clarify several points in the manuscript.

\section{References}

Anderson, T.R., and P. J. le B. Williams, A one-dimensional model of dissolved organic carbon cycling in the water column incorporating combined biological-photochemical decomposition, Global Biogeochem. Cycles, 13, 337-349, 1998.

Basturk, O., C. Saydam, I. Salihoglu, L. V. Eremeeva, S. K. Konovalov, A. Stoyanov, A. Dimitrov, A. Cociasu, L. Dorogan, and M. Altabet, Vertical variations in the principle chemical properties of the Black Sea in the autumn of 1991, J. Mar. Chem., 45, 149-165, 1994.

Basturk, O., S. Tugrul, S. Konovalov, and I. Salihoglu, Variations in the vertical structure of water chemistry within the three hydrodynamically different regions of the Black Sea, in Sensitivity to Change: Black Sea, Baltic Sea and North Sea, NATO Sci. Partnership Sub-ser., 2, vol.27, edited by E. Ozsoy and A. Mikaclyan, pp. 183-196, Kluwer Acad., Norwell, Mass., 1997.

Basturk, O., I. I. Volkov, S. Gokmen, H. Gungor, A.S Romanov, and E.V. Yakushev, International expedition on board R/V Bilim in July 1997 in the Black Sea, Oceanology, Engl. Transl., 38, 429-432, 1998.

Belyaev, V.I., and N.V. Konduforova, Modelling of the shelf ecosystem, Ecol. Modell., 60, 95-118, 1992.

Belyaev, V.I., E.E. Sovga, and S.P. Lyubartseva, Modelling the hydrogen sulfide zone of the Black Sea, Ecol. Modell., $9651-59,1997$.

Brewer, P.G., and D.W. Spencer, Distribution of some trace elements in the Black Sea and their flux between dissolved and particulate phases, in The Black Sea-Geology, Chemistry, and Biology edited by E.T. Degens and D.A. Ross, 
Mem. 20, pp. 137-143, Am. Assoc. of Petrol. Geol., Tulsa, Oklo., 1974.

Broecker, W.S., and T.H. Peng, Tracers in the sea, 690 pp., Lamont-Doherty Earth Observatory, Palisades, New York, 1982.

Buesseler, K.O., H.D. Livingston, L. Ivanov, and A. Romanov, Stability of the oxic-anoxic interface in the Black Sea, Deep Sea Res., Part I, 41, 283-296, 1994.

Codispoti, L.A., G.E. Friederich, J.W. Murray, and C. M. Sakamoto, Chemical variability in the Black Sea: Implications of continuous vertical profiles that penetrated the oxic/anoxic interface, Deep Sea Res., 38, suppl 2, S691S710, 1991.

Eremeev, V.N., Hydrochemistry and dynamics of the hydrogen sulphide zone in the Black Sea, in Unesco reports in marine Science, edited by R.C. Griffiths, 114 pp., United Nations Educ., Sci., and Cult. Org., Paris, 1996.

Francis, C.A., and B.M. Tebo, Marine bacillus spores as catalysts for oxidative precipitation and sorption of metals, J. Mol. Microbiol. Biotechnol., 1, 71-78, 1999.

Friederich, G.E., L.A. Codispoti, and C.M. Sakamato, Bottle ans pumpcast data from the Black Sea expedition, Tech. Rep. 90-3, 224pp., Monterey Aquarium Res. Inst., Monterey, 1990.

Gargett, A.E., Vertical eddy diffusivity in the ocean interior, J. Mar. Res., 42, 359-393, 1984.

Gregg, M.C., and E. Ozsoy, Mixing on the Black Sea shelf north of the Bosphorus, Geophys. Res. Lett., 26, 1869$1872,1999$.

Gregoire, M., J.M. Beckers, J.C.J. Nihoul, and E. Stanev, Reconnaissance of the main Black Sea's ecohydrodynamics by means of a 3D interdisciplinary model, J. Mar. Syst., 16, 85-106, 1998.

Ishii, H., and U. Bamstedt, Food regulation of growth and maturation in a natural population of Aurelia aurita, $J$. Plankton Res., 20, 805-816, 1998.

Ivanov, L.I., and T. Oguz, Ecosystem Modeling as a Management Tool for the Black Sea, vol. 1 and 2, NATO Sci. Partnership Sub-ser., 2, vol. 47, Kluwer Acad., Norwell, Mass., 1998.

Jasby, A.D., and R. T. Platt, Mathematical formulation of the relationship between photosynthesis and light for phytoplankton, Limnol. and Oceanogr., 21, 540-547, 1976.

Karl, D.M., and G.A. Knauer, Microbial production and particle flux in the upper $350 \mathrm{~m}$ of the Black Sea, Deep Sea Res., 38, supp. 2A, S655-S661, 1991.

Kempe, S., Coastal Seas: A net source or sink of atmospheric carbon dioxide?, LOICZ rep. and stud. 1, $27 \mathrm{pp}$, Land-Ocean Interaction in the Coastal Zone, Texel, Netherlands, 1995.

Kempe, S., A.R. Diercks, G. Liebezeit, and A. Prange, Geochemical and structural aspects of the pycnocline in the Black Sea (R/V Knorr 134-8 Leg 1, 1988), in Black Sea Oceanography, edited by E. Izdar and J.W. Murray, pp. 89-110, NATO Sci. Partnership Sub-ser., C, vol. 351, Kluwer Acad. Publ., Netherlands, 1991.

Kideys, A. E., A.V. Kovalev, G. Shulman, A. Gordina, and F. Bingel, A review of zooplankton investigations of the Black Sea over the last decade, J. Mar. Syst., 24, 355-371, 2000.

Konovalov, S., S. Tugrul, O. Basturk, and I. Salihoglu, Spatial isopycnal analysis of the main pycnocline chemistry of the Black Sea, in Sensitivity to change: Black Sea, Baltic Sea and North Sea, NATO Sci. Partnership Sub-ser., 2, vol.27, edited by E. Ozsoy and A. Mikaelyan, pp. 197-210, Kluwer Acad., Norwell, Mass., 1997.

Konovalov, S.K., L.I. Ivanov, J. W. Murray, and L.V. Ere- meeva, Eutrophication: A plausible cause for changes in hydrochemical structure of the Black Sea anoxic layer, in Environmental degradation of the Black Sea: Challenges and Remedies, NATO Sci. Partnership Sub-ser., 2, vol.56, edited by S.T. Besiktepe, U. Unluata, and A.S. Bologa, pp. 61-74, Kluwer Acad., Norwell, Mass., 1999.

Kovalev, A.V., U. Nierman, V.V. Melnikov, V. Belokopytov, Z. Uysal, A.E. Kideys, M. Unsal, and D. Altukhov, Longterm changes in the Black Sea zooplankton: the role of natural and anthropogenic factors, in Ecosystem Modeling as a Management Tool for the Black Sea, vol. 1, NATO Sci. Partnership Sub-ser., 2, vol. 47, edited by L.I. Ivanov, and T. Oguz, pp. 221-234, Kluwer Acad., Norwell, Mass., 1998.

Lancelot, C., J. Staneva, D. Van Eeckhout, E. Stanev, and J.M. Beckers, Modeling the impact of the human forcing on the ecological functioning of the northwestern Black Sea, Estuarine Coastal Shelf Sci., in press, 2000.

Lebedeva, L.P., and E.A. Shushkina, Evaluation of population characteristics of the medusae Aurelia aurita in the Black Sea, Oceanology, Engl. Transl., 31, 314-319, 1991.

Lebedeva, L.P., and E.A. Shushkina, Modelling the effect of Mnemiopsis on the Black Sea plankton community, Oceanology, Engl. Transl., 34, 72-80, 1994.

Lewis, B.L., and W.M. Landing, The biogeochemistry of manganese and iron in the Black Sea, Deep Sea Res., 38, suppl. 2A, S773-S804, 1991.

Lipschultz, F., S.C. Wofsy, B.B. Ward, L.A. Codispoti, G. Friedrich, and J.W. Elkins, Bacterial transformations of inorganic nitrogen in the oxygen-deficient waters of the Eastern Trophical South Pacific Ocean, Deep Sea Res., 37, 1513-1541, 1990.

Lyubartseva, S.P., and V. G. Lyubartsev, Modeling of the Black Sea anoxic zone processes, in Ecosystem Modeling as a Management Tool for the Black Sea, vol. 1, NATO Sci. Partnership Sub-ser., 2, vol. 47, edited by L.I. Ivanov, and T. Oguz, pp. 385-396, Kluwer Acad., Norwell, Mass., 1998.

Mee, L.D., The Black Sea in crisis: A need for concerted international action, Ambio, 21, 278-286, 1992.

Millero, F.J., The oxidation of $\mathrm{H}_{2} \mathrm{~S}$ in the Black Sea waters, Deep Sea Res., 38, suppl. 2A, S1139-S1150, 1991.

Murray, J.W., H. W. Jannash, S. Honjo, R. F. Anderson, W.S. Reeburgh, Z. Top, G.E. Friederich, L.A. Codispoti, and E. Izdar, Unexpected changes in the oxic/anoxic interface in the Black Sea, Nature, 338, 411-413, 1989.

Murray, J.W., L.A. Codispoti, and G.E. Friederich, Oxidation-reduction environments: The suboxic zone in the Black Sea, in Aquatic chemistry: Interfacial and interspecies processes, ACS Adv. in Chem. Ser., vol. 224, edited by C.P. Huang, C.R. O'Melia, and J.J. Morgan, pp. 157-176, Am. Chem. Soc., Washington, D.C., 1995.

Murray, J.W., B.S. Lee, J. Bullister, and G.W. Luther III, The suboxic zone of the Black Sea, in Environmental Degradation of the Black Sea: Challenges and Remedies, NATO Sci. Partnership Sub-ser., 2, vol.56, edited by S.T. Besiktepe, U. Unluata, and A.S. Bologa, pp. 75-92, Kluwer Acad., Norwell, Mass., 1999.

Mutlu, E., Distribution and abundance of ctenophores and their zooplankton food in the Black Sea, II, Mnemiopsis leidyi, Mar. Biol., 135, 603-613, 1999.

Neumann, T., T. Leipe, and G. Shimmield, Heavy-metal enrichment in surficial sediments in the Oder River discharge area: Source or sink for heavy metals?, Appl. Geochem., 13, 329-337, 1998.

Nezlin, N.P., A.G. Kostianoy, and M. Gregoire, Patterns of seasonal and interannual changes of surface chlorophyll 
concentrations in the Black Sea revealed from the remore sensed data, Remote Sens. Environ., 69, 43-55, 1999.

Oguz, T., H. Ducklow, P. Malanotte-Rizzoli, S. Tugrul, N. Nezlin, and U. Unluata, Simulation of annual plankton productivity cycle in the Black Sea by a one-dimensional physical-biological model, J. Geophys. Res., 101, 16585$16599,1996$.

Oguz, T., H. Ducklow, P. Malanotte-Rizzoli, and J.W. Murray, Simulations of the Black Sea pelagic ecosystem by one dimensional vertically resolved physical-biogeochemical models, Fish. Oceanogr., 7, 300-304, 1998.

Oguz, T., H. Ducklow, P. Malanotte-Rizzoli, J.W. Murray V.I. Vedernikov, and U. Unluata, A physical-biogeochemical model of plankton productivity and nitrogen cycling in the Black Sea, Deep Sea Res., Part 1, 46, 597-636, 1999

Oguz, T., J. W. Murray and A.E. Callahan, Modeling redox cycling across the suboxic-anoxic interface zone in the Black Sea, Deep Sea Res., Part I, in press, 2000.

Ozsoy, E. and A.S. Mikaelyan, Sensitivity to Change: Black Sea, Baltic Sea and North Sea, NATO Sci. Partnership Sub-ser., 2, vol.27, 469 pp., Kluwer Acad., Norwell, Mass., 1997.

Purcell, J.E. and P. Kremer, Feeding and metabolism of the siphonophore Sphaeronectes gracilis, J. Plankton Res., 5, 95-106, 1983.

Rozanov, A.G., Redox stratification in Black Sea waters, Oceanology, Engl. Transl., 35, 500-504, 1996.

Saydam, C., S. Tugrul, O. Basturk, and T. Oguz, Identification of the oxic/anoxic interface by isopycnal surfaces in the Black Sea, Deep Sea Res., 40, 1405-1412, 1993.

Shiganova, T.A., Invasion of the Black Sea by the ctenophore Mnemiopsis leidyi and recent changes in pelagic community structure, Fish. Oceanogr., 7, 305-310, 1998.

Shushkina, E.A., Y.I. Sorokin, L.P. Lebedeva, A.F. Pasternak, and E.E. Koshevskaya, Production and destruction characteristics of plankton community in the northeastern part of the Black Sea during 1978 (in Russian), in Seasonal Variations of Black Sea Plankton, edited by Y.I. Sorokin and V.I. Vedernikov, pp. 178-200, Nauka, Moscow, 1983.

Shushkina, E.A., M.E. Vinogradov, L.P. Lebedeva, T. Oguz, N.P. Nezlin, V. Yu. Dyakonov, and L.L. Anokhina, Studies of structural parameters of planktonic communities of the open part of the Black Sea relevant to ecosystem modeling, in Ecosystem Modeling as a Management Tool for the Black Sea, vol. 1, NATO Sci. Partnership Sub-ser., 2, vol. 47, edited by L.I. Ivanov, and T. Oguz, pp. 311-326, Kluwer Acad., Norwell, Mass., 1998.

Sullivan, B.K., J.R. Garcia, and G. Klein-Macphee, Prey selection by the scyphomedusan predator Aurelia aurita, Mar. Biol., 121, 335-341, 1994.

Stoecker, D.K, A.E. Michaels, and L.H. Davis, Grazing by the jellyfish, Aurelia aurita, on microzooplankton, $J$. Plankton Res., 9, 901-915, 1987.

Tebo, B. M., Manganese(II) Oxidation in the Suboxic Zone of the Black Sea. Deep Sea Res., 38, supp. 2A, S883-S905, 1991

Tebo, B.M., and A.Y. Obraztsova, Sulfate-reducing bacterium grows with $\mathrm{Cr}(\mathrm{VI}), \mathrm{U}(\mathrm{VI}), \mathrm{Mn}(\mathrm{IV})$, and $\mathrm{Fe}(\mathrm{III})$ as electron acceptors, FEMS Microbiol. Lett., 162, 193-198, 1998.

Thomsen, U., and E. Kristensen, Dynamics of sigma $\mathrm{CO}_{2}$ in a surficial sandy marine sediment: The role of chemoautotrophy, Aquatic. Microbial Ecol., 12, 165-176, 1997.

Tugrul, S., O. Basturk, C. Saydam, and A. Yilmaz, The use of water density values as a label of chemical depth in the Black Sea, Nature, 359, 137-139, 1992.

United Nations Education, Science, and Cultural Organi- zation (UNESCO), Progress on oceanographic tables and standards 1983-1986: work and recommendations of the UNESCO/SCOR

/ICES/IAPSO Joint Panel, Tech. Pap. Mar. Sci., 50, 50 pp., 1996

Vedernikov, V.I., and A.B. Demidov, Primary production and Chlorophyll in deep regions of the Black Sea. Oceanology, Engl. Transl., 33, 193-199, 1993.

Vedernikov, V.I., and A.B. Demidov, Vertical distribution of primary production and chlorophyll during different seasons in deep regions of the Black Sea, Oceanology, Engl. Transl., 37, 376-384, 1997.

Vinogradov, M. E., E.A. Shushkina, A.S. Mikaelyan, and N.P. Nezlin, Temporal (seasonal and interannual) changes of ecosystem of the open waters of the Black Sea, in Environmental degradation of the Black Sea: Challenges and Remedies, NATO Sci. Partnership Sub-ser., 2, vol. 56, edited by S.T. Besiktepe, U. Unluata, and A.S. Bologa, pp. 109-129, Kluwer Acad., Norwell, Mass., 1999.

Walsh, J.J., et al., Simulation of carbon-nitrogen cycling during spring upwelling in the Cariaco Basin, J. Geophys. Res., 104, 7807-7825, 1999.

Ward, B.B., and K.A. Kilpatrick, Nitrogen transformations in the oxic layer of permanent anoxic basins: The Black Sea and Cariaco Trench, in Black Sea Oceanography, edited by E. Izdar and J.W. Murray, pp. 111-124, NATO Sci. Partnership Sub-ser., C, vol. 351, Kluwer Acad. Publ., Netherlands, 1991.

Warren, B.A., Context of the suboxic layer in the Arabian Sea, in Biogeochemistry of the Arabian Sea: Present information and gaps, edited by D. Lal, Proc. Indian Acad. Sci., 103, 301-314, 1994.

Yakushev, E.V. and L.N. Neretin, One dimensional modeling of nitrogen and sulfur cycles in the aphotic zone of the Black and Arabian Seas, Global Biogeochem. Cycles, 11, 401-414, 1997.

Yao, W., and F.J. Millero, The rate of sulfide oxidation by $\mathrm{MnO}_{2}$ in seawater, Geochem. Cosmochim. Acta, 57 , 3359-3365, 1993.

Yilmaz, A., O.A. Yunev, V.I. Vedernikov, S. Moncheva, A.S. Bologa, A. Cociasu, and D. Ediger, Unusual temporal variations in the spatial distribution of chlorophyll-a in the Black Sea during 1990-1996, in Ecosystem Modeling as a Management Tool for the Black Sea, vol. 1, NATO Sci. Partnership Sub-ser., 2, vol. 47, edited by L.I. Ivanov, and T. Oguz, pp. 105-120, Kluwer Acad., Norwell, Mass., 1998.

Zaitsev, Y., Impacts of eutrophication on the Black Sea fauna, General Fisheries Council for the Mediterranean, Stud. Rev., 64, Food and Agricultural Organization, pp. 63-86, 1993.

Zaitsev, Yu. and V. Mamaev, Marine Biological Diversity in the Black Sea: A Study of Change and Decline, 208 pp., Global Environmental Facility, Black Sea Environ. Prog., New York, 1997

H. W. Ducklow, Virginia Institute of Marine Sciences, College of William and Mary, Gloucester Point, VA 23062. (duck@vims.edu)

P. Malanotte-Rizzoli, Massachusettes Institute of Technology, Department of Earth, Atmospheric and Planetary Sciences, Cambridge, MA 02139. (rizzoli@ocean.mit.edu)

T. Oguz, Middle East Technical University, Institute of Marine Sciences, Erdemli, Icel, Turkey. (oguz@ims.metu.edu.tr)

(Received December 22, 1999; revised May 17, 2000; accepted May 24, 2000.) 